Article

\title{
Investigation of Electrical Conductivity, Optical Property, and Stability of 2D MXene Nanofluid Containing Ionic Liquids
}

\author{
Balaji Bakthavatchalam ${ }^{1}\left(\mathbb{D}\right.$, Khairul Habib ${ }^{1, *(\mathbb{D},}$, R. Saidur ${ }^{2,3}$, Navid Aslfattahi ${ }^{4}(\mathbb{D}$ \\ and A. Rashedi ${ }^{5, *}$ \\ 1 Department of Mechanical Engineering, Universiti Teknologi PETRONAS, \\ Bandar Seri Iskandar 32610, Malaysia; balaji_17004028@utp.edu.my \\ 2 Research Centre for Nano-Materials and Energy Technology (RCNMET), School of Science and Technology, \\ Sunway University, Petaling Jaya 47500, Malaysia; saidur@sunway.edu.my \\ 3 Department of Engineering, Lancaster University, Lancaster LA1 4YW, UK \\ 4 Department of Mechanical Engineering, Faculty of Engineering, University of Malaya, \\ Kuala Lumpur 50603, Malaysia; navid.fth87@siswa.um.edu.my \\ 5 College of Engineering, IT \& Environment, Charles Darwin University, Ellengowan Drive, \\ Casuarina 0810, Australia \\ * Correspondence: khairul.habib@utp.edu.my (K.H.); mabrur.rashedi@cdu.edu.au (A.R.)
}

Received: 25 November 2020; Accepted: 13 December 2020; Published: 15 December 2020

check for updates

Featured Application: Analysing the effect of ionic liquids in Mxene nanofluids using UV-Vis spectroscopy attributes to the enhancement of photothermal performance of solar systems.

\begin{abstract}
The addition of ionic liquids with MXene nanofluid has a substantial impact on the solar thermal collectors' working fluid's optical properties that effectively absorb and distribute solar radiation. Increased solar radiation absorption potential ensures that heats are transported more rapidly and effectively. This research endeavors to investigate the concept of accumulating solar energy via the usage of ionic liquid-based 2D MXene nanofluid (Ionanofluids) for solar applications. In this study, the optical potential of Diethylene Glycol/MXene nanofluid incorporated with 1-ethyl-3-methyl imidazolium octyl sulfate ([Emim] $\left.\left[\mathrm{OSO}_{4}\right]\right)$ ionic liquid was extensively investigated with respect to MXene concentration ( 0.1 to $0.4 \mathrm{wt} \%$ ) and time (first day and seventh day) through UV-Vis Spectroscopy. A two-step approach was employed to synthesize the proposed ionanofluids with nanoparticle concentrations from 0.1 to $0.4 \mathrm{wt} \%$. In wavelengths between 240 to $790 \mathrm{~nm}$, the effect of ionic liquids, MXene concentration, and dispersion stability played a significant part in enhancing the absorbance capacity of the formulated MXene based Ionanofluid. Furthermore, the increase in the concentration of MXene nanoparticles resulted in more absorbance peaks facilitating high light absorption. Finally, the electrical conductivity of the ionanofluids is also analyzed as MXene renders them promising for solar cell applications. The utmost electrical conductivity of the formulated fluids of $571 \mu \mathrm{S} / \mathrm{cm}$ (micro siemens per centimeter) was achieved at $0.4 \mathrm{wt} \%$ concentration.
\end{abstract}

Keywords: 2D MXene; ionic liquids; nanofluids; electrical; optical; stability; spectroscopy

\section{Introduction}

The usage of solar power is one of the key alternatives to the issue of global warming, rising energy demands, and declining energy sources. It is estimated that the volume of solar energy on the Earth's surface is over 20,000 times that needed at present by humans to create the impression of inexhaustibility. We need transportable and conveniently processed energy for the optimal usage of any energy source. 
This implies that the incoming solar energy should be effectively stored or transported, which can be achieved through a solar thermal system. Thus, solar energy can contribute to significant savings of common energy resources like coal, oil, and natural gas. Solar thermal systems are non-polluting and do not emit greenhouse gases during their operation. They could also save considerable fossil fuel and electricity consumption, which is currently used for domestic applications [1,2] since conventional heat transfer fluids have many limitations, such as poor thermal conductivity, high viscosity, uncontrollable pressure drop, and pumping power. Researchers have found a new class of heat transfer fluid (HTF) called 'nanofluids', which is defined as a colloidal suspension of nanosized solid particles incorporated with common base fluids to obtain superior thermophysical properties such as thermal conductivity, viscosity, density, and specific heat capacity. In general, these fluids are mainly utilized for cooling, however, there is not enough research to describe its potential in electronic devices where electrical conductivity is a major concern. Owing to the creation of an electrical double layer, the nanoparticles scattered in the base fluids are charged along the particle surface in nanofluids. When a chargeis applied, these nanoparticles migrate effectively to the oppositely charged electrode leading to high electrical conductivity. Poongavanam et al. [3] reported a comprehensive review of nanofluidselectrical conductivity in recent applications.

Therefore, this study concentrated on exploring the electrical and optical potential of nanofluids containing MXene and ionic liquid-based solvent. Compared to optical properties, nanofluids' thermal properties have been investigated for a long time in numerous researches. Recent studies on the optical investigation of nanofluids are summarized as follows: Gheymasi et al. [4] compared the optical property of $\mathrm{ZnO}$ nanoparticles dispersed with different base fluids (DMSO, DMF, DI water, and ethanol) at different volume concentrations and laser intensity. The authors observed a unique saturation absorption and self-defocusing behavior for $\mathrm{ZnO} / \mathrm{DMSO}$ nanofluid, which can be used for non-linear optical devices. Unfortunately, the authors have not discussed the optical properties of the tested nanofluids towards different temperature ranges. Aguilar et al. [5] used graphene oxide nanoparticles with a base fluid containing a mixture of biphenyl and diphenyl oxide. They reported that graphene oxide addition increased the extinction coefficient in the entire wavelength of the spectrum, proving the presence of heat transfer fluid-absorption band, which is responsible for the heat transfer process enhancement. Li et al. [6] explored the advantage of Si-MWCNT/EG nanofluids on the performance of a direct absorption solar collector (DASC). In the infrared and visible regions of UV spectroscopy, the authors obtained remarkable solar irradiation absorption. Moreover, 99.9\% of solar energy was absorbed in $0.5 \mathrm{wt} \%$ of SiC-MWCNT nanofluid, making them a potential candidate as an HTF for DASC. However, they have not considered other important factors, such as pressure drop and pumping power. In an interesting study, Valizade et al. [7] distinguished the optical property of $\mathrm{SiC} /$ water and $\mathrm{CuO} /$ water nanofluid porous metal foam in a DASC. They pointed out that the thermal efficiency of absorption solar collectors depends mainly on the optical properties of absorbers. Their results indicated that for lower wavelengths (200-900 nm), the extinction coefficient increased for $\mathrm{CuO} /$ water nanofluid, while porous foam showed a higher extinction coefficient at higher wavelengths. Rosa et al. [8] provided another delightful nanodiamond/EG nanofluid to use in solar collectors. They found a significant increase in the extinction coefficient at the UV region for the tested nanofluid, while above the infrared region, the extinction coefficient was fully dependent on the suspension's base fluid. From the above literature, it was clear that nanoparticles addition dramatically increased the optical performance of nanofluids. Nevertheless, all the above researchers used conventional base fluids such as EG, water, or oil in the nanofluids. Since these traditional coolants' decomposition temperature or thermal stability is very low $\left(<200^{\circ} \mathrm{C}\right)$, they are not preferred for high-temperature applications. Furthermore, these fluids have many limitations, such as high vapor pressure, less chemical, and thermal stability. As a result, researchers are focused on developing innovative nanofluids with excellent optical and electrical properties that can be used for a different range of applications.

In recent years, ionic liquids have sparked substantial attention in their possible application for solar energy processing as they are optically transparent for both UV and visible regions. Ionic liquids 
are novel organic salts consisting of anions and cations that exist in the liquid state at room temperature. Meanwhile, the literature suggests that ionic liquids possess fascinating properties such as negligible vapor pressure, high thermal stability, dispersibility, and eco-friendly nature, which are favorable for utilizing it as a base fluid for formulating nanofluids. For instance, Zhang et al. [9] investigated the optical properties of ionic liquid-based nanofluids ([HMIM][NTf 2$] / \mathrm{Ni}$ ) in DASC. They demonstrated that ionic liquid-based solutions containing nickel-coated carbon nanoparticles obtained a maximum extinction coefficient with less transmittance, making them a promising HTF for solar thermal collectors. In the same way, ionanofluids were synthesized and improved thermal properties were seen relative to pure ionic liquids. Owing to the fascinating properties of two-dimensional (2D) materials, which are peculiar from three-dimensional (3D) analogs, research on 2D materials increases researchers' attention. 2D MXenes are imperative in applications such as energy storage, energy conversion, lubrication, and batteries due to their significant surface area, making them draw much interest in solar applications. This motivated the present study to analyze the optical property of imidazolium-based ionic liquids dispersed with MXene nanofluid. A comprehensive exploration of nanofluids' significant properties and ionic liquids has been made by Bakthavatchalam et al. [10]. Consequently, with a growing research focus on 2D materials, a form of new materials identical to graphene called MXene has been paid much attention. Usually, it consists of transition metal carbides or nitrides produced by its parent MAX phase's chemical etching. Das et al. [11] dispersed 1,3-Dimethylimidazolium dimethyl-phosphate ionic liquid with water/MXene nanofluid to improve the efficiency of a hybrid PV/T solar system. Stability and optical property were improved with a maximum thermal efficiency of $13.95 \%$. Abdelrazik et al. [12] experimentally investigated the optical, stability, and energy performance of water/MXene nanofluid solar thermal systems. The authors observed an enhancement in the PV/thermal solar systems' optical and thermal efficiency even at low concentrations of MXene. Bao et al. [13] prepared nanofluids containing MXene nanoparticles and ethylene glycol base fluid and analyzed its potential for application as heat transfer fluids. The authors reported a thermal conductivity enhancement of $64.9 \%$ without any nanoparticle sedimentation for 30 days. The magnificent optical property, thermal conductivity and stability of MXene combined with high aspect ratio make it a promising nanofluid candidate.

At present, researches are mainly focused on improving the thermal properties of nanofluids containing conventional nanoparticles such as graphene, aluminum, copper, and iron. However, optical properties at different wavelengths and optical stability have to be analyzed to obtain comprehensive information about light absorption in nanofluids. In the present study, multilayer MXene is synthesized with $\mathrm{NH}_{4} \mathrm{HF}_{2}$ chemical etchant and dispersed in a binary base fluid ([Emim][oso 4 ]+Diethylene Glycol) to prepare a novel 2D Mxene ionanofluid. The optical property and stability of four types of MXene nanofluids at different weight concentrations have been evaluated extensively. Furthermore, the electrical conductivity and $\mathrm{pH}$ of the formulated samples were also investigated with respect to MXene nanoparticle concentration. The optical stability and extinction coefficient (optical property) of the as-prepared MXene ionanofluid are higher than conventional nanofluids. High MXene concentrated samples showed more fluctuations because of diffraction peaks in all the regions (UV, visible, and IR region). Additionally, the electrical conductivity results show that all samples' conductivity increased with an increase in MXene nanoparticle concentration. This research's main novelty is the enhancement of optical stability and electrical property by adding [EMIM][OSO $\mathrm{OS}_{4}$ ionic liquid to 2D MXene nanofluid. This study could be a benchmark for developing heat transfer fluids based on 2D materials and ionic liquids.

\section{Materials and Methods}

\subsection{Materials}

1-ethyl-3-methyl imidazolium octyl sulfate ([EMIM][OSO 4 ]) ionic liquid with a molecular weight of $348.50 \mathrm{~g} / \mathrm{mol}$, purity of $\geq 98 \%$, and water content of $\leq 1 \%$ was bought from Merck group, Germany, the characteristics of which are discussed in our previous literature [14]. Diethylene glycol (CAS No. 
111-46-6), which is to be mixed with the ionic liquid, was also procured from the same company. Chemicals used in the synthesis of MXene such as hydrochloric acid $(\mathrm{HCl})$, sodium fluoride, and sodium hydroxide with the highest purity levels were acquired from Sigma Aldrich, USA. Elemental nanopowder of titanium (Ti), aluminum ( $\mathrm{Al}$ ), and titanium carbide (TiC) was also obtained from Sigma Aldrich.

\subsection{Synthesis and Characterization of MXene Nanoparticles}

To obtain the MAX phase of $\mathrm{Ti}_{3} \mathrm{AlC}_{2}$, the powders of titanium, aluminium, and titanium carbides were mixed in the ratio of 1:1.2:2 followed by thermal treatment in a furnace. This mixture was heated for $120 \mathrm{~min}$ at a temperature of $1400{ }^{\circ} \mathrm{C}$ with a constant Argon gas flow. To graft the $\mathrm{Al}$ layer from the $\mathrm{Ti}_{3} \mathrm{AlC}_{2} \mathrm{MAX}$ powder, the reduction process was carried out by $\mathrm{NH}_{4} \mathrm{HF}_{2}$ etchant, similar to the previous report [15]. To obtain an optimum $\mathrm{pH}$ (around 6), hydrochloric acid and sodium hydroxide solutions were added and stirred slowly after the etching process. The supernatant was removed by the centrifugation process, which was conducted at a speed of 3000 RPM for $15 \mathrm{~min}$. Then, the resulted solution was washed with deionized water, and it was dried for $12 \mathrm{~h}$ in a vacuum desiccator. Finally, the $\mathrm{Al}$ layer was removed from the $\mathrm{Ti}_{3} \mathrm{AlC}_{2} \mathrm{MAX}$ phase leading to the formation of MXene $\left(\mathrm{Ti}_{3} \mathrm{C}_{2}\right)$ sheets. Figure 1 shows the procedure of etching and resulting $\mathrm{Ti}_{3} \mathrm{C}_{2}$ structure from $\mathrm{Ti}_{3} \mathrm{AlC}_{2}$.

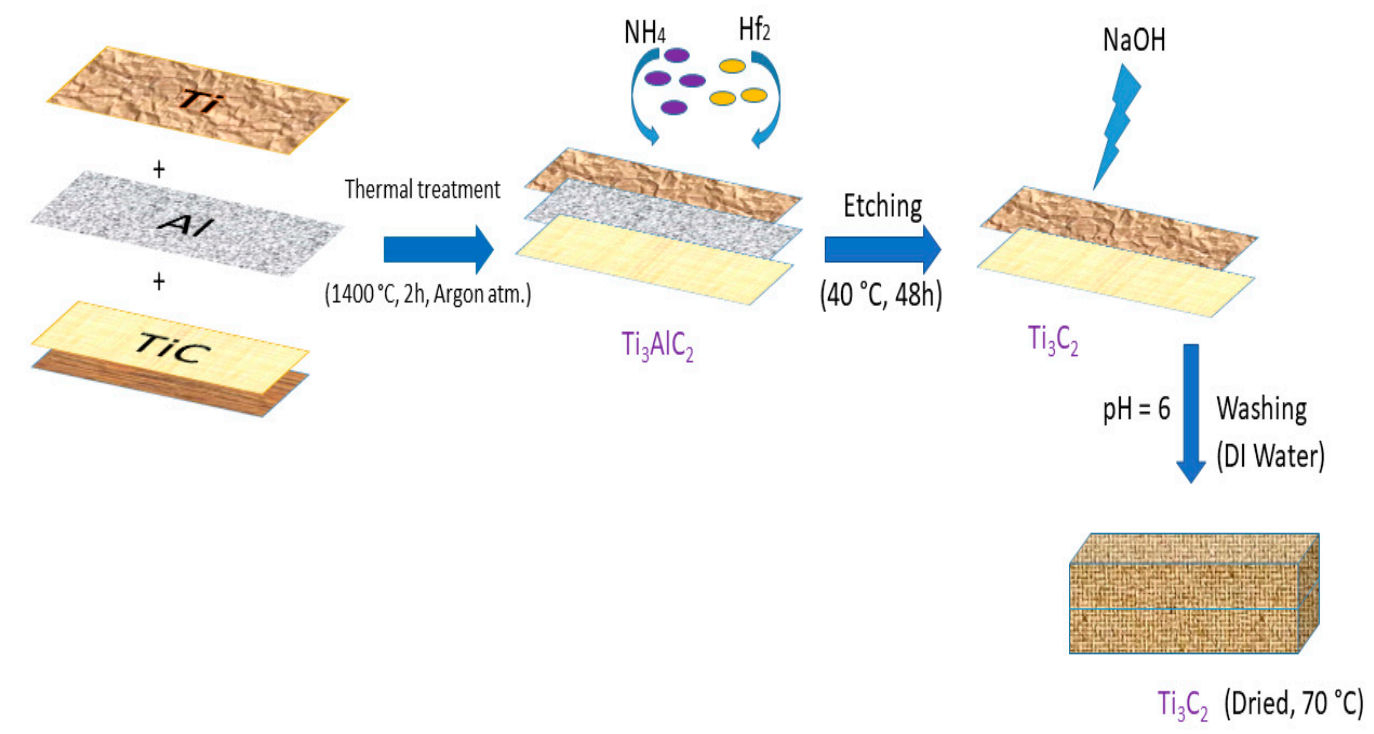

Figure 1. Schematics of MXene $\left(\mathrm{Ti}_{3} \mathrm{C}_{2}\right)$ synthesis from MAX phase $\left(\mathrm{Ti}_{3} \mathrm{AlC}_{2}\right)$.

With Zeiss Supra 55 VP Field-Emission Scanning Electron Microscope and Energy Disperse X-ray (EDX), the surface topology and chemical composition of the synthesized MXene nanoparticles were characterized. In a Scanning Electron Microscope, the field-emission SEM (FESEM) offered both low and high energy beams for narrow sights, which enhanced spatial resolution and reduced sample charging and loss.

\subsection{Preparation of Ionic Liquid-Based MXene Nanofluid}

The synthesized MXene powder was dispersed in a binary solution ([EMIM][OSO 4$]+$ DG) to formulate four ionic liquid-based nanofluids through a two-step method followed by ultrasonication for $2.5 \mathrm{~h}$. The sample's temperature was maintained at atmospheric temperature using a water circulating bath to avoid the samples overheating. The formulated fluids were prepared at four different mass concentrations, comprising $0.1,0.2,0.3$, and $0.4 \mathrm{wt} \%$ of MXene nanoparticles. For $0.1 \mathrm{wt} \%$ ([EMIM] $\left.\left[\mathrm{OSO}_{4}\right]+\mathrm{DG}\right) / \mathrm{MXene}$ nanofluid, $0.05 \mathrm{~g}$ of MXene was added to $4.995 \mathrm{~g}$ of [EMIM][OSO 4 ionic liquid and $44.955 \mathrm{~g}$ of diethylene glycol in a $100 \mathrm{~mL}$ beaker. Around $1000 \mathrm{RPM}$ without heating, the mixture was then agitated with a magnetic agitator for $30 \mathrm{~min}$. Using an ultrasonic probe, the mixture 
was sonicated for about $90 \mathrm{~min}$ with $60 \%$ power leading to a homogenous dispersion. The other samples with $0.2,0.3,0.4 \mathrm{wt} \%$ concentration were also formulated by following the procedure mentioned above.

\subsection{Optical Property and Stability Characterization}

\subsubsection{UV-Vis Spectroscopic Analysis of Ionic Liquid-Based MXene Nanofluid}

UV-Vis/NIR spectrometer (Lambda 750, PerkinElmer, Waltham, MA, USA) with a wavelength range of 190 to $3300 \mathrm{~nm}$ was employed to determine the absorption spectra of the as-prepared ionic liquid-based nanofluid at room temperature. Spectrometers usually comprise a light source, monochromator, detector, and an amplifier with an indicator. Here, the beam light was separated by a prism into variable wavelengths. The prepared samples were poured into a cuvette distanced by an optical length of $10 \mathrm{~mm}$ and placed inside the device. For cuvettes produced from unique optical glass, some of the illuminations were lost by reflections on the cuvette's surfaces. To remove this type of error, a comparable calculation was carried out in a cuvette of the same distance but not the material to be calculated. In this study, the standard cuvette contained deionized water (pure solvent), which does not absorb in the spectral region under consideration. A light beam was then passed through the solutions in the cuvettes, which absorbed the UV or visible radiation. The ultraviolet light absorbed by the studied samples generated a specific spectrum that helped to identify the electron transition and chemical compounds. Based on the light beam's solution concentration and path length, the amount of light absorption varied. If the solution did not absorb any light, the transmittance would be $100 \%$.

\subsubsection{Absorbance Analysis to Evaluate the Stability or Degradation of Nanofluids}

An innovative approach to determine the stability of nanofluids was proposed in this research. In this technique, nanofluid absorbance was calculated at different intervals for its stability after preparation. The stability or lifespan of a nanofluid depends on the sedimentation rate of nanoparticles. Since sedimentation influences nanofluids absorbance, analyzing the difference in nanofluids absorbance over time may be used to assess its stability. The formulated ionanofluids' absorbance spectra were measured by a Lambda 750 UV-Vis Spectrometer (PerkinElmer) on the first and seventh day after preparation. The obtained results were used to assess the change of absorbance rate over time, illustrating nanofluids stability.

\subsubsection{Stability Analysis Using Visual Inspection Method}

In the second stage, nanofluid stability was characterized using the Visual Inspection Technique. It is a process in which the aggregation or sedimentation of nanoparticles with respect to time is examined with the naked eye. The prepared ionic liquid-based nanofluids were suffused in transparent vials, and their changes were observed for one week. Based on the appearance, the nanofluids' stability was examined.

\subsection{Electrical Conductivity and $\mathrm{pH}$ Measurement}

The $\mathrm{pH}$ and electrical conductivity of the samples were measured using a conductivity meter (3540 conductivity/pH meter, JENWAY, Staffordshire, UK) at $298 \mathrm{~K}$. The specifications were as follows: $\mathrm{pH}$ range of -2 to 20 ; conductivity range of $0.01 \mu \mathrm{S}$ to $1.99 \mathrm{~S}$; temperature range of -10 to $105^{\circ} \mathrm{C}$; temperature coefficient of 0 to $4 \% /{ }^{\circ} \mathrm{C}$. The combined $\mathrm{pH}$ and conductivity meter were calibrated with pure diethylene glycol. 


\section{Results and Discussion}

\subsection{Morphology and Chemical Composition}

\subsubsection{FESEM Analysis}

With spatial resolution up to $1.5 \mathrm{~nm}$ or better, FESEM creates smoother and less electrostatically blurred pictures, many times better than the traditional SEM. Good resolution, low-voltage pictures were accomplished with marginal sample electric charge (acceleration voltages vary between 0.5 and $30 \mathrm{kV}$ ). The FESEM images of the synthesized MXene nanoparticles at different magnifications are shown in Figure 2. From the image, it was clear that the three-dimensional $\mathrm{Ti}_{3} \mathrm{AlC}_{2} \mathrm{MAX}$ powder was converted to multilayer $\mathrm{Ti}_{3} \mathrm{C}_{2}$ which demonstrated the grafted $\mathrm{Al}$ layer from $\mathrm{Ti}_{3} \mathrm{AlC}_{2}$ using $\mathrm{NH}_{4} \mathrm{HF}_{2}$ etchant. One of the significant parameters that affect the thermophysical properties of MXene nanofluid is the thickness of the synthesized MXene nanosheets, which consist of many layers. These layers also decide the suitability of 2D materials in functional devices such as supercapacitors, batteries, and semiconductors. In this study, the average thickness of each layer ranged from 70 to $90 \mathrm{~nm}$, which was in line with previous literature results [16,17]. On observing the thickness of the MXene layers, it could be noted that some layers showed loosely packed structures creating interspace between the MXene layers providing fluidic channels for base fluids.

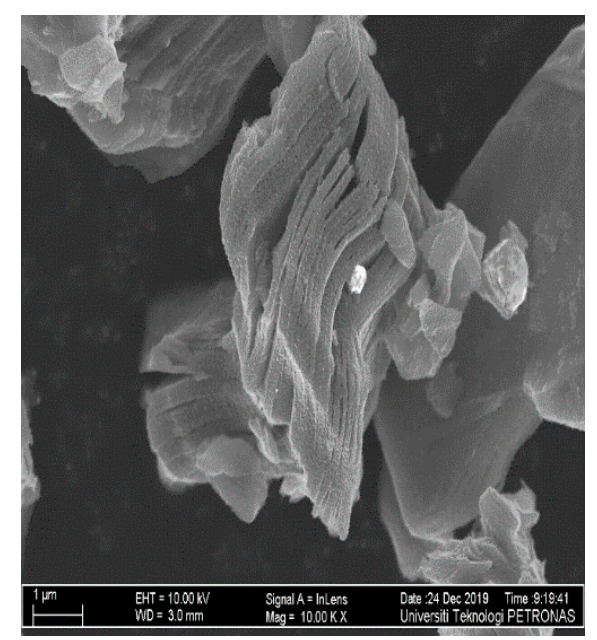

(a)

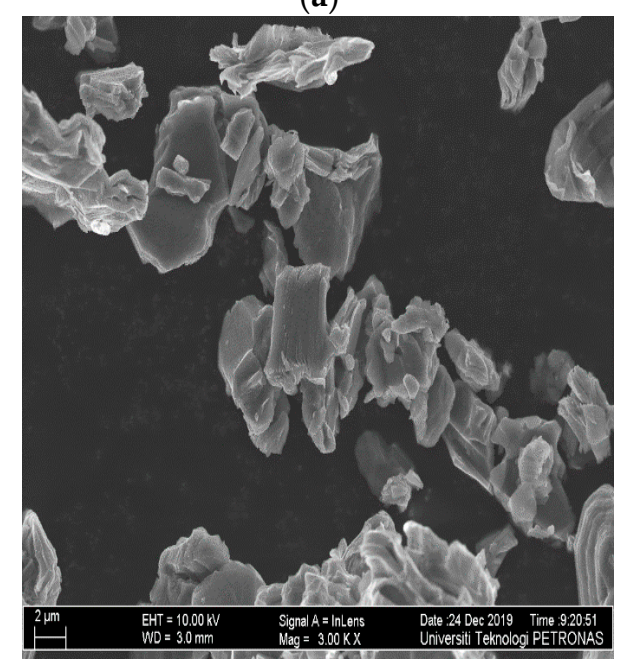

(c)

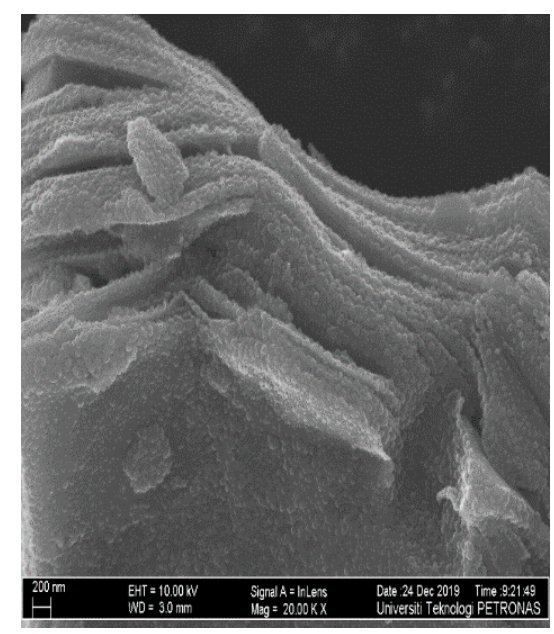

(b)

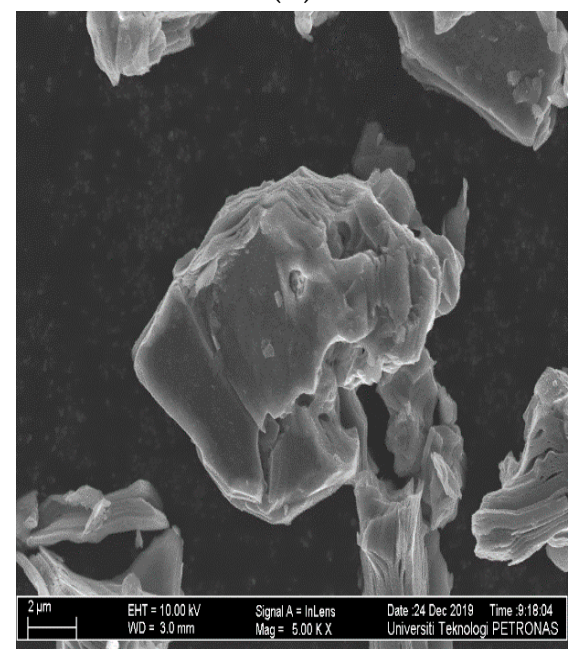

(d)

Figure 2. FESEM images of $(\mathbf{a}, \mathbf{b})$ Cross-sectional view of $\mathrm{Ti}_{3} \mathrm{C}_{2}$ MXene after drying (c,d) Top view of the synthesized $\mathrm{Ti}_{3} \mathrm{C}_{2}$ MXene after delamination. 
The FESEM image (Figure 2a,b) clearly illustrates the structure of MXene sheets. The chemical etching method exfoliated the MXene layers, and the corresponding sheets revealed a topography identical to the previous study [18]. Figure 2c,d indicates the synthesized MXene sheets formed because of the delamination process, which led to the production of 2D MXene sheets whose size was less than $2 \mu \mathrm{m}$.

\subsubsection{EDX Analysis}

The necessary data was collected through a samples-electron beam-interaction detector, which collected X-rays from the samples. The characteristic X-rays generated for elements was typically distinct from element to element, with a few spectral peaks overlapping due to the electron energy levels' quantization. When the elements of one peak were unclear, other peaks or a small background of the sample history could contribute to the fair detection of elements. Even with a single point of $0.2 \mathrm{~nm}$ or by shifting the light beam anywhere in the sample, the elemental map could be generated.

Figure 3a shows the image of the sample where the electron beam was passed. From the image, the formation of 2D MXene flakes could be confirmed. Figure $3 b$ depicts the concentration of different elements in the synthesized MXene nanoparticle. From the peaks of the graph, it was confirmed that titanium (52.85 wt\%), oxides (22.81 wt \%), and carbide (10.23 wt\%) composition was higher when compared to other elements. Moreover, small traces of aluminum (2.98 wt\%), chlorine $(2.64 \mathrm{wt} \%)$, and fluoride $(8.5 \mathrm{wt} \%$ ) were also present.

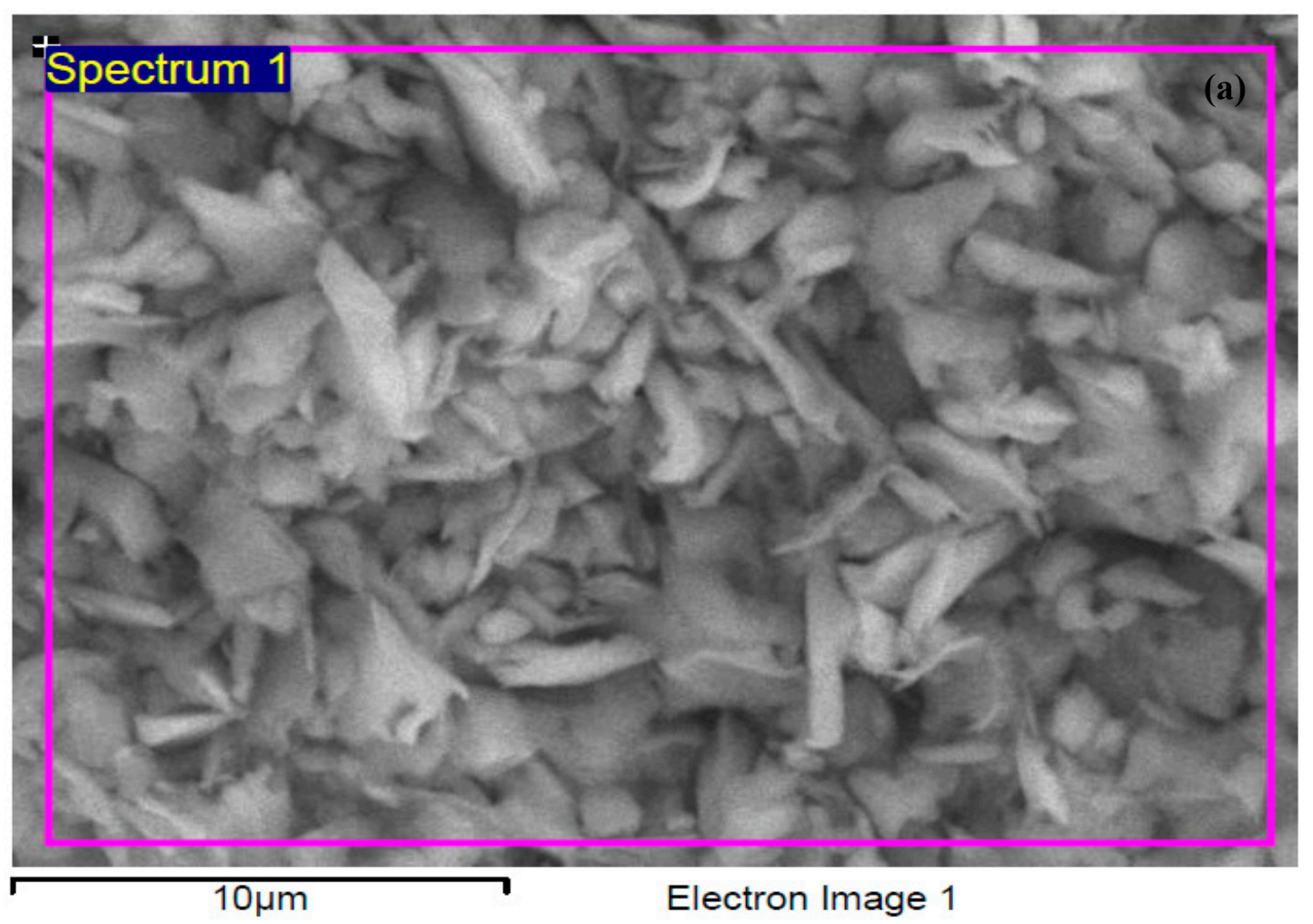

Figure 3. Cont. 


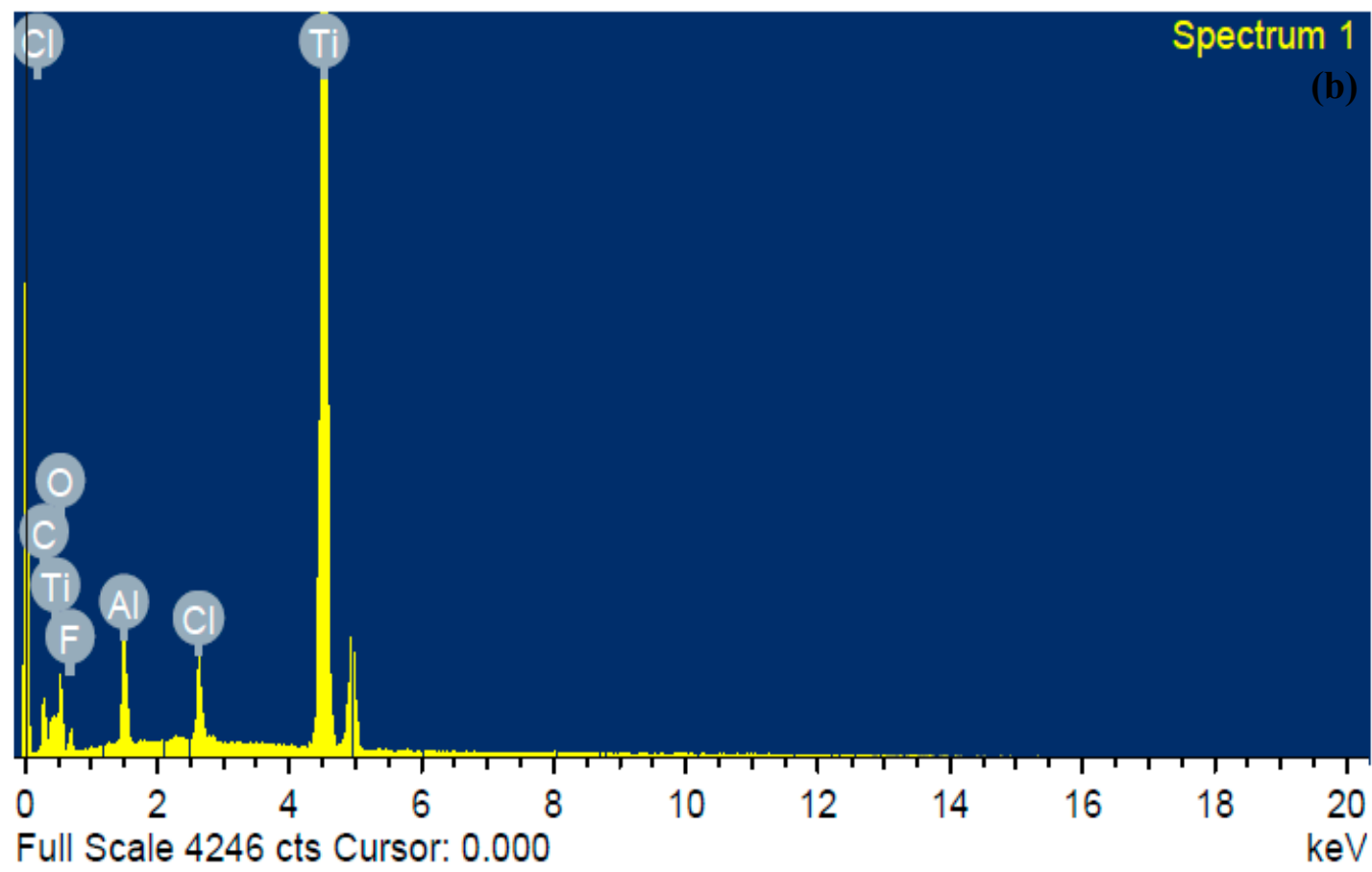

Figure 3. Images of (a) Spot at which EDX analysis is performed (b) EDX graph of the synthesized MXene.

\subsubsection{EDX Mapping}

The X-ray mapping of elements is another significant and useful aspect of EDX technology. $\mathrm{A}$ unique color identifies the concentration of different elements that discharge $\mathrm{X}$-rays in the inspection area. In Figure 4, the maps of titanium (Ti), carbide $(\mathrm{C})$, aluminium $(\mathrm{Al})$, fluoride $(\mathrm{F})$, chlorine $(\mathrm{Cl})$, oxides $(\mathrm{O})$, and sulphur $(\mathrm{S})$ are shown separately and overlaid with the original image (Electron image 1). From the results of EDX mapping, it was possible to confirm a larger amount of titanium and carbides, which are the main constituents of the 2D MXene.

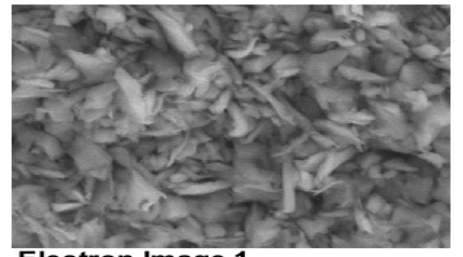

Electron Image 1

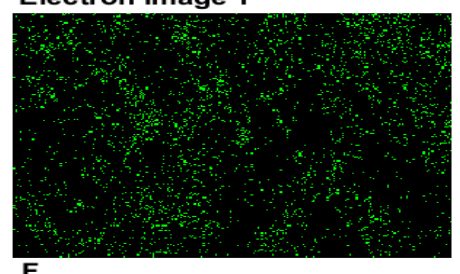

$\mathbf{F}$

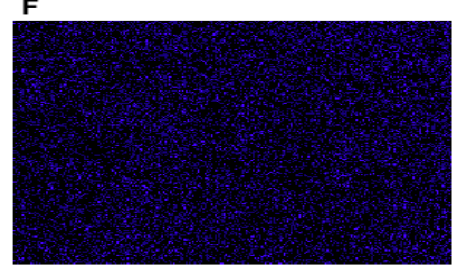

Cl

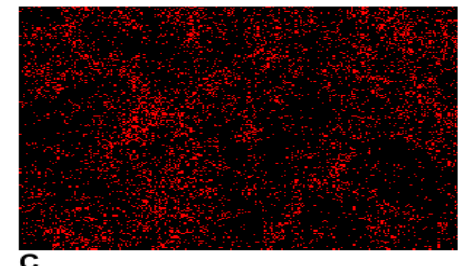

C

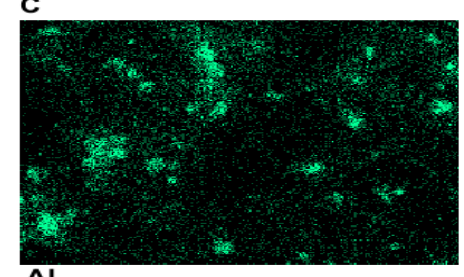

Al

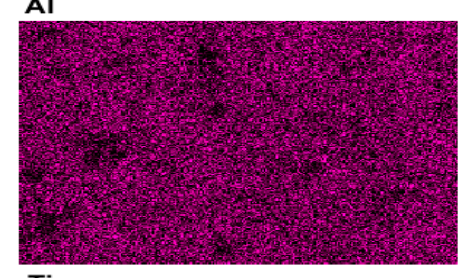

$\mathbf{T i}$

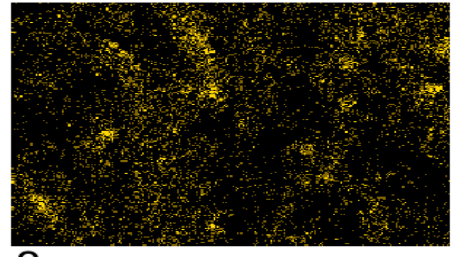

o

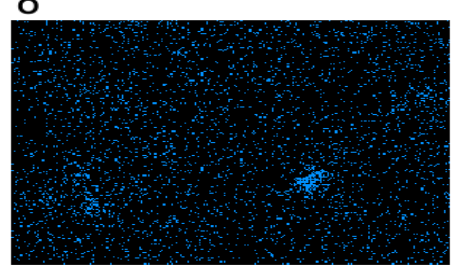

s

Figure 4. EDX mapping of the synthesized MXene nanoparticle. 


\subsection{Effect of Ionic Liquid on the Electrical Conductivity and $p H$ of MXene Nanofluid}

Ionic liquids' efficiency is mainly affected by its high viscosity and mild conductivity. The simple way to overcome this problem is to add conventional solvents with ionic liquids that can minimize the viscosity, improve the electrical conductivity, and reduce cost. One of the elements that can be used for this reason is diethylene glycol (DG), as DG's polarity can provide outstanding solvation and thus significantly increase the binary blends' electrical conductivity. The electrical conductivity of pure DG, ionic liquid-based DG, and ionic liquid-based Mxene/DG nanofluid with different mass concentrations at a temperature of $298 \mathrm{~K}$, measured on the first day, is shown in Figure 5. From the results, the electrical conductivity enhancement was consistent with the addition of ionic liquids and Mxene nanoparticles, which could be attributed to the interaction of cations and anions of ionic liquids and steric effects which resulted in the increase of energy for the as-prepared samples. The electrical conductivity increased with an increase in nanoparticles' mass concentration, and a maximum value of $571 \mu \mathrm{S} / \mathrm{cm}$ was obtained for $0.4 \mathrm{wt} \%$. There was a significant improvement in the prepared mixtures' electrical conductivity than the pure diethylene glycol owing to the presence of high charge carriers in Mxene and ionic liquids. Increasing the concentration of ionic liquids in the mixture could increase the number of charge carriers. Still, at the same time, the viscosity of the sample would be increased, which reduced the mobility of the charge carriers resulting in less electrical conductivity.

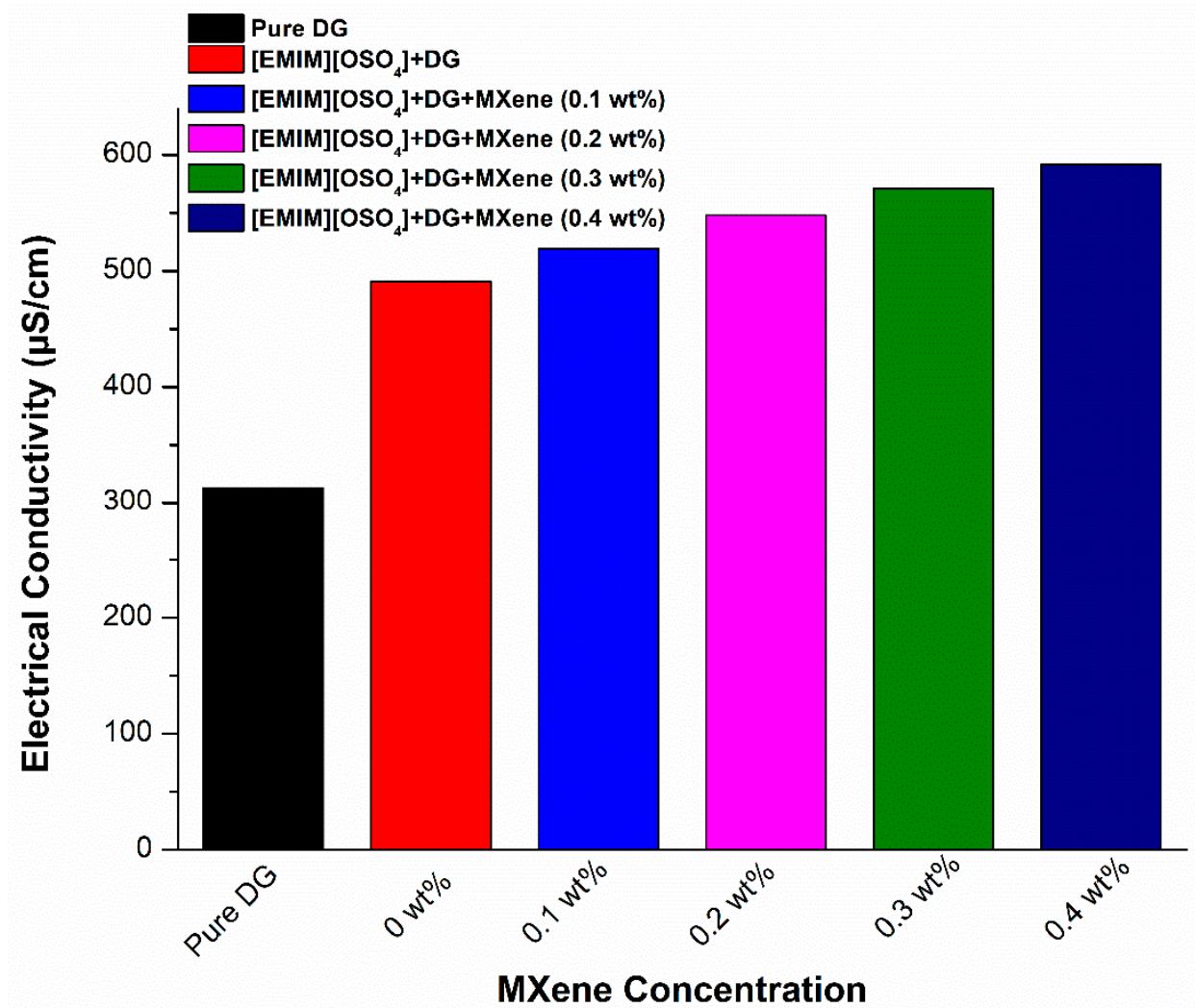

Figure 5. Electrical conductivity of the ionanofluids at different mass concentrations.

The dispersion stability and heat transfer properties of nanosuspensions can be enhanced by controlling the $\mathrm{pH}$ value. In general, surface hydroxyl groups and phenyl sulfonic groups undergo interaction at an optimized $\mathrm{pH}$ value, leading to increased repulsive forces resulting in less accumulation, improved heat transfer, and superior mobility. However, the suspension shows less stability when the $\mathrm{pH}$ value is too large due to electrical double layer compression usually caused by a $\mathrm{pH}$ adjustment reagent, which decreases the electrostatic repulsion. Therefore, the utmost care has to be taken in maintaining the $\mathrm{pH}$ of the samples. Figure 6 displays the $\mathrm{pH}$ of the as-prepared samples that varied 
from 5.85 to 6.19 , which clearly illustrates that no appreciable changes were observed for the proposed samples with Mxene nanoparticles' addition.

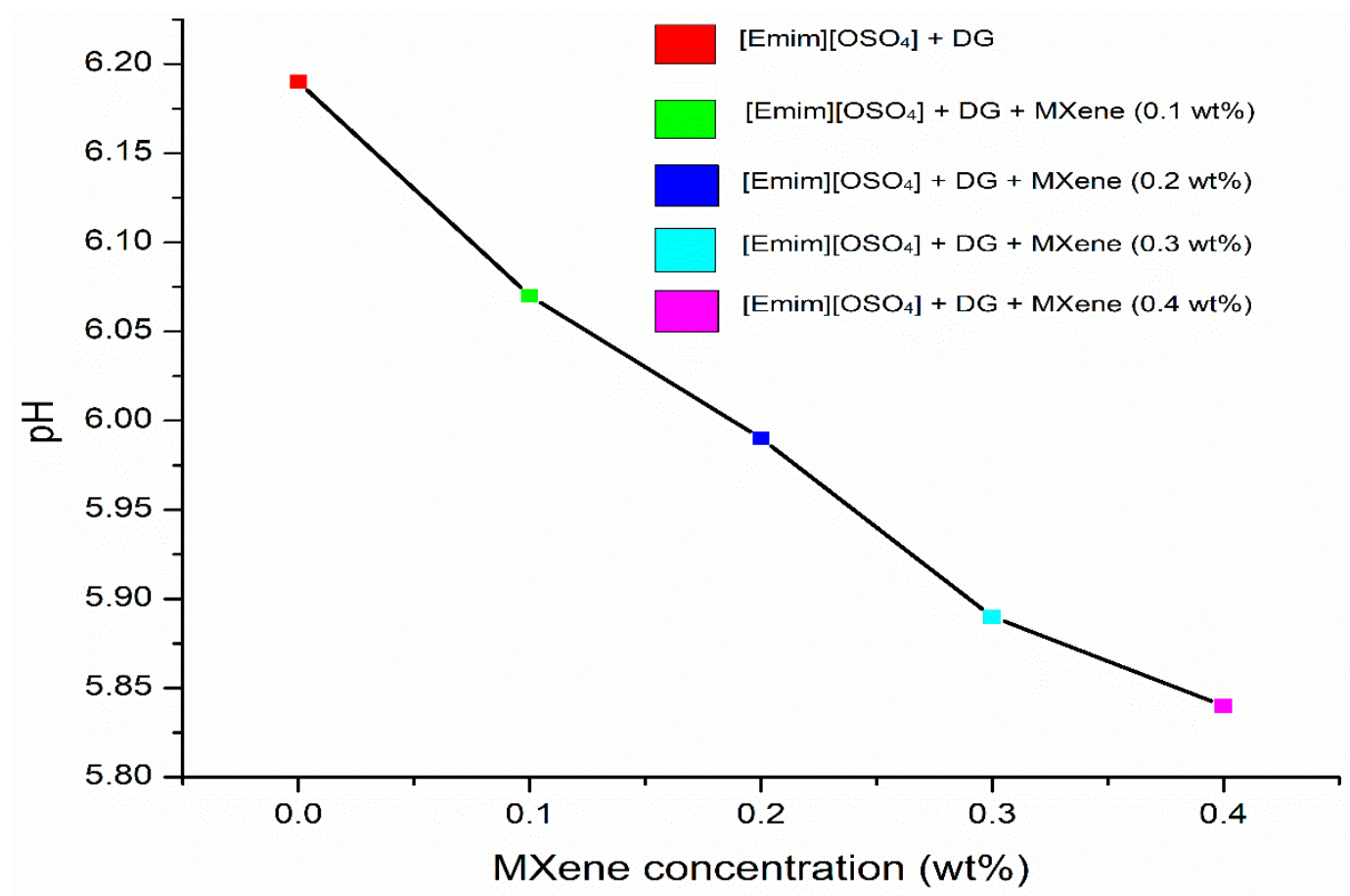

Figure 6. Variation of $\mathrm{pH}$ for different concentrations of Mxene nanoparticles.

\subsection{UV-Vis Absorption Spectrum Analysis}

UV spectroscopy is an absorption spectroscopy method that absorbs light in the ultraviolet region via the molecule, which causes electrons to excite from the ground energy state to a high energy state. Besides, spectroscopy is the process of analyzing electromagnetic radiation received or released when the samples' molecules move from one energy level to another energy level. The significant aspect of ionanofluids is to store or transfer the ample solar energy into practical energy that allows energy to be stored during sunlight and used at night. This form of energy is known as adsorptive energy that can be calculated in various wavelengths using UV-Vis spectrometry. The studied samples containing different weight percentages of MXene/DG nanofluid incorporated with $[\mathrm{Emim}]\left[\mathrm{OSO}_{4}\right]$ ionic liquid were subjected to UV-Vis Spectrometry using Perkin Elmer Lambda 750 equipment.

\subsubsection{Light Absorption Spectra of Base Fluid ([Emim][OSO 4$]+$ DG)}

The UV-Vis absorption, scattering, reflection, and fluorescence are observed when an object is subjected to a light beam in a UV-Vis Spectrometer. In the absorption process, the electromagnetic radiation interacts with the objects or solution in the cuvette, where a small part of the radiation gets converted to another form of energy, namely heat. The tested base fluid's optical absorption spectra on the first and seventh day are presented in Figure 7a,b. The amount of light absorbed is indicated in the vertical axis, which can also be called absorbance. More absorption on a particular wavelength results in a higher absorbance value.

The tested base fluid spectrum showed the maximum absorbance value at 200 to $300 \mathrm{~nm}$ wavelength (UV region), which was in good agreement with previous literature [15]. Depending on the absorption of photons, UV-Vis peaks could be smaller or larger. The absorption of large numbers of photons leads to larger peaks. The peak observed at $243 \mathrm{~nm}$ in the UV-Vis spectrum of the base fluid (Figure $7 \mathrm{a}$ ) attributed to the conjugation of $\pi$ electron transition ( $\pi-\pi^{*}$ transition) from the lowest unoccupied molecular orbital (LUMO) to the highest occupied molecular orbital (HOMO). The conjugated aromatic domains contributed to the peak that was seen in the UV region of $270-300 \mathrm{~nm}$. 
Due to the increase in the concentration of $\pi$ electrons and changes in atoms' arrangement, the intensity of absorption in the spectral region (Visible, IR) decreased dramatically. To evaluate the absorption stability, the sample was tested after 7 days (Figure 7b), where the absorption peak was found at $256 \mathrm{~nm}$ with higher absorbance, presumably due to the slow reaction of ionic liquids with diethylene glycol [19]. After $300 \mathrm{~nm}$, there were not any peaks observed that could be contributed by the destruction of electronic conjugation during the etching process of MXene.

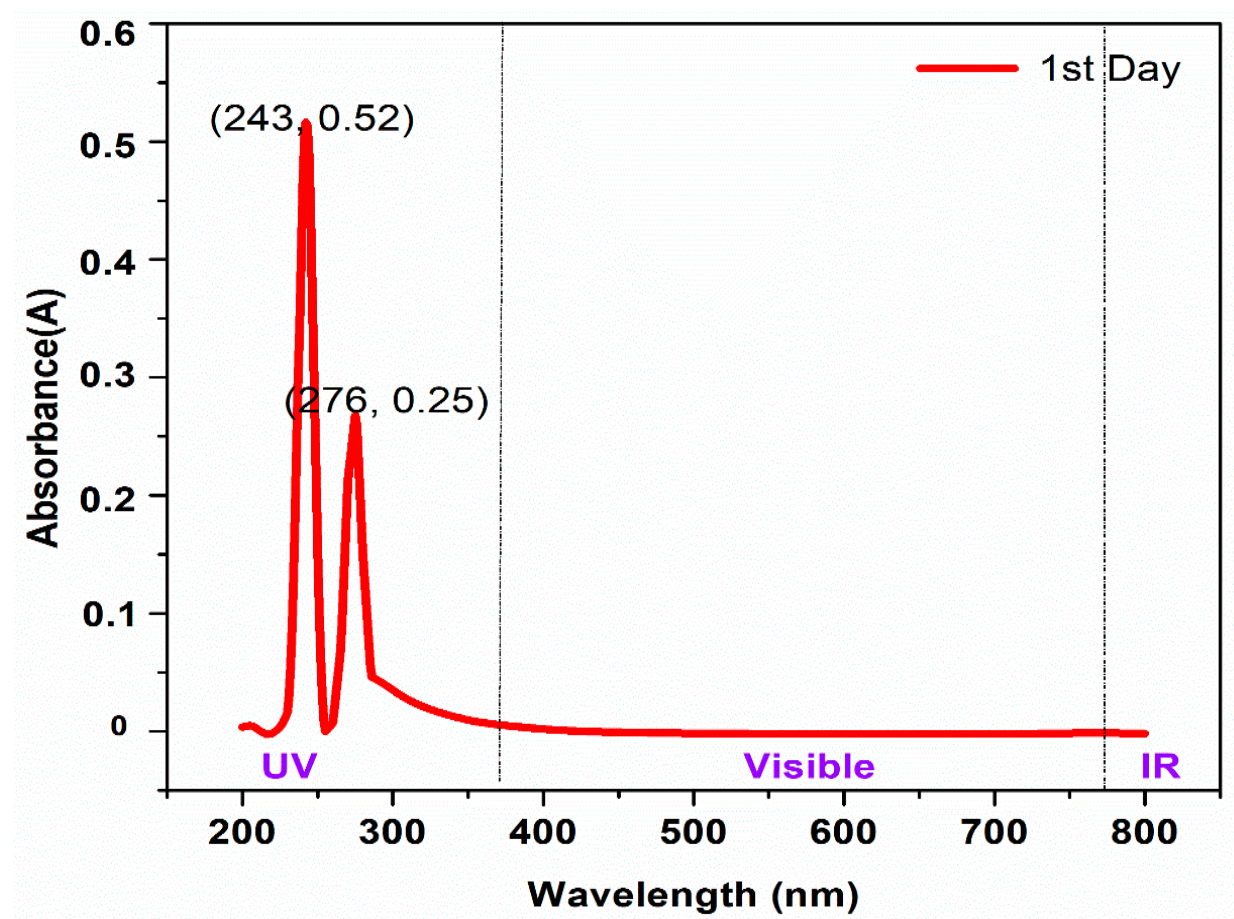

(a)

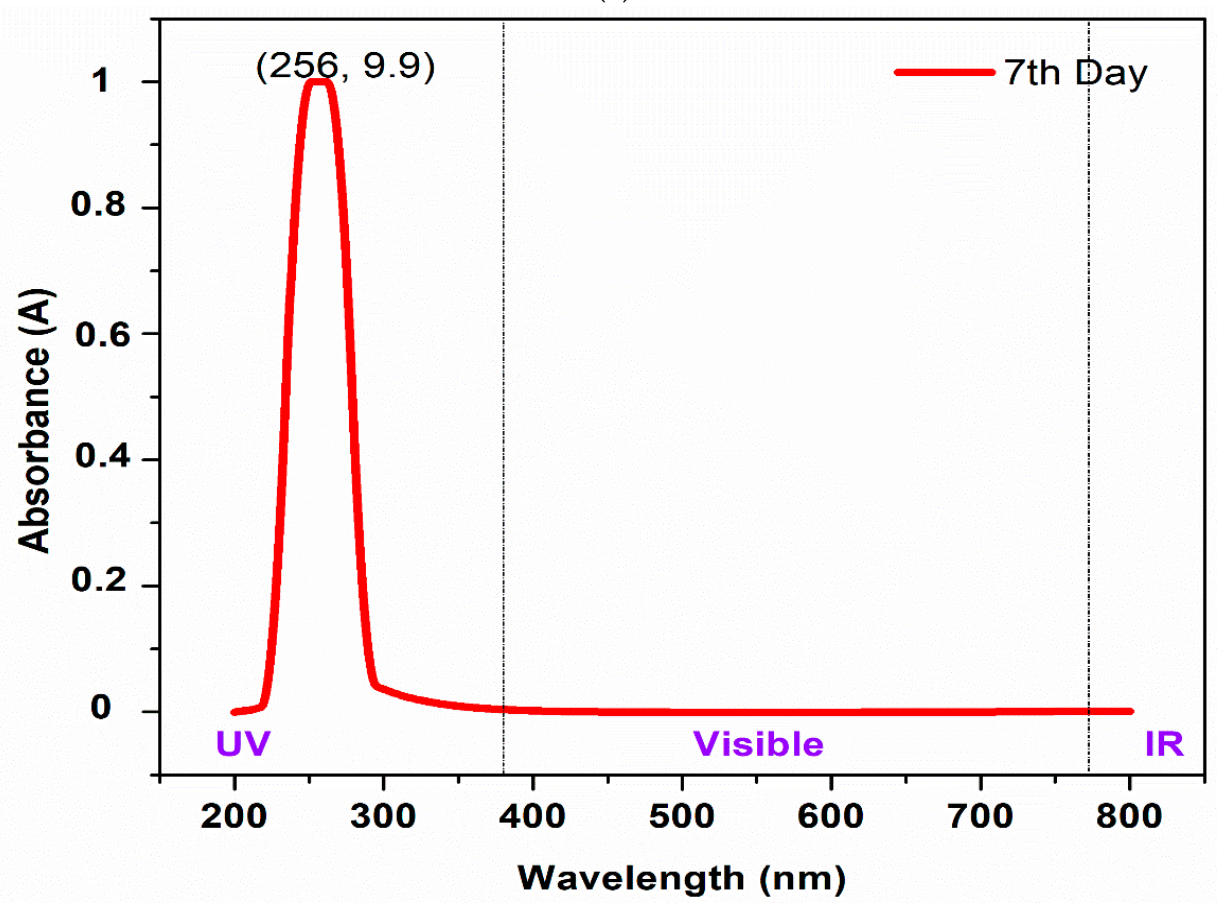

(b)

Figure 7. UV-Vis absorbance spectra of the base fluid on the (a) first day and (b) the seventh day. 


\subsubsection{Light Absorption Spectra of the MXene Based Ionanofluid}

Electronic transition (excitation of electrons to a higher energy state from the ground state) occurs when UV and visible radiation interacts with objects. The UV region falls in the wavelength range between 10 to $380 \mathrm{~nm}$, and the visible region falls between 380 to $780 \mathrm{~nm}$. The possible transitions are pi to pi star $\left(\pi-\pi^{*}\right), \mathrm{n}$ to pi star ( $\mathrm{n}-\pi^{*}$ transition), sigma to sigma star ( $\sigma-\sigma^{*}$ transition), and $\mathrm{n}$ to sigma $\operatorname{star}\left(\mathrm{n}-\sigma^{*}\right.$ transition). The transition from $\sigma$ to $\sigma^{*}$ electrons needs a wavelength of light absorption that does not fall in the UV-Vis range. Therefore, the UV-Vis region can show the only $\pi$ to $\pi^{*}$ and $n$ to $\pi^{*}$ transition. The visible region possesses 36 to $76 \mathrm{kcal} / \mathrm{mol}$ of photon energies, while the UV region (>200 nm wavelength) has photon energies of $143 \mathrm{kcal} / \mathrm{mol}$, which is needed to promote electrons to higher energy orbital. In photocatalytic, photovoltaic, optoelectronic, transparent conducting electrode instruments, the visible and UV light absorption are significant. The absorbance spectral curves were plotted using the UV-Vis spectrometer measurements.

Nanofluids comprising $\pi$ electrons and $n$ electrons (non-bonding electrons) absorb energy as UV light to stimulate these electrons into higher molecular orbitals. Figure 8 demonstrates the ionic liquids' effect on the absorbance spectra of the formulated DG/MXene nanofluid on the first day for 0.1 to $0.4 \mathrm{wt} \%$ mass concentration. For the first day and seventh day, a direct relationship was found between the MXene concentration and the absorbance spectra of the as-prepared DG/MXene nanofluid containing [EMIM] $\left[\mathrm{OSO}_{4}\right]$ ionic liquid. The effect of ionic liquid and the MXene nanoparticle concentration was detected in the range of 240 to $800 \mathrm{~nm}$, which attributes to the region of UV, visible, and infrared. The absorbance of all as-prepared samples escalated intermittently with the decreasing wavelength of 240 to $800 \mathrm{~nm}$. Nanofluid with lower nanoparticle concentration $(0.1 \mathrm{wt} \%)$ showed limited absorbance spectra at the UV region, whereas high concentrated samples $(0.2$ to $0.4 \mathrm{wt} \%)$ showed more absorbance peaks in all regions. Within the visible range of 380 to $780 \mathrm{~nm}$, a wide absorbance spectrum was observed that became noticeable with the MXene concentration rise, which was due to the surface plasmon resonance of MXene nanoparticles. These results confirmed that MXenes can absorb light at UV as well as visible regions when combined with aqueous solutions. From the graph, it was clear that the maximum absorption peaks for $0.1,0.2,0.3$, and $0.4 \mathrm{wt} \%$ concentration were observed at the UV region of range 220 to $380 \mathrm{~nm}$, which was due to the transition of $\pi-\pi^{*}$ and $\mathrm{n}-\pi^{*}$ electrons. These transitions were mainly caused by $\mathrm{C}=\mathrm{C}$ and $\mathrm{C}=\mathrm{O}$ functional groups' bonding, which was very similar in carbon and graphene-based nanofluids. For $0.1 \mathrm{wt} \%$, there was no sign of light being absorbed in the visible region, which meant that the only electron jumps that took place were from $\pi$ bonding to $\pi$ antibonding orbitals. Additionally, except for $0.1 \mathrm{wt} \%$ concentration, all the other samples showed absorbance peaks over a whole range of given wavelengths confirming a whole range of energy jumps. This occurred when the vibrations and transformations in the molecules shifted the orbitals' energies, constantly leading to the change of energy gap between them. As a consequence, absorption happened over several wavelengths rather than one specific wavelength.

The measured absorbance spectra of the prepared ionanofluids on the seventh day after preparation is depicted in Figure 9. It was observed that the ionic liquid-based MXene nanofluids have limited optical absorbance in the UV and visible light wavelengths when compared to the first day. This illustrated a similar trend with less efficiency to that of the previous ionanofluid as indicated in Figure 8. As seen in the image, the indisputable absorbance enhancement was found in the UV region of 200 to $380 \mathrm{~nm}$ wavelength, implicating the ionic liquid-based MXene nanofluids' ability to harvest solar energy. However, less concentrated MXene nanofluid ( $0.1 \mathrm{wt} \%)$ showed an obvious reduction of light absorbance after $330 \mathrm{~nm}$. On the other hand, the increase of nanoparticle concentration led to many UV and visible region peaks. Therefore, increasing the concentration of MXene nanoparticles could make better light absorbance in the visible region than the UV region, which is favorable for solar energy harvesting. The presence of many absorbance peaks, especially on the first day, demonstrated that an increase in optical absorption in the UV and visible regions of MXene nanofluids could effectively capture solar energy, which would enable the prepared samples to have successful photovoltaic applications. 


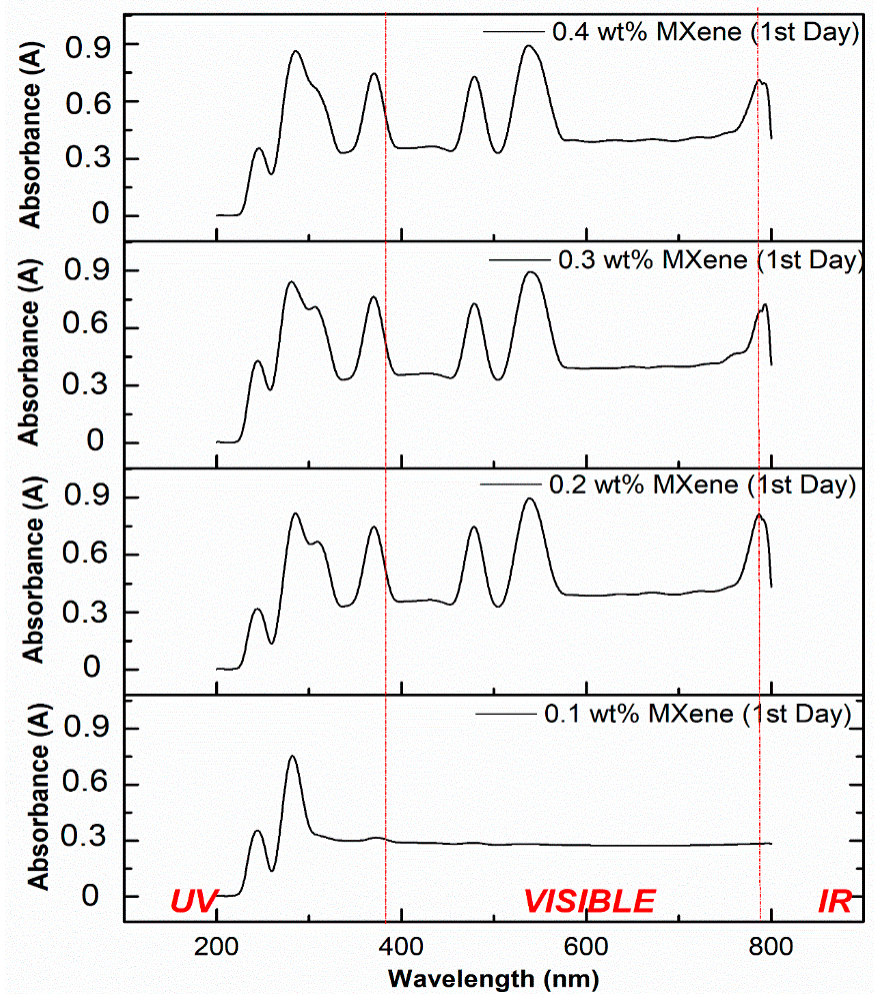

Figure 8. Absorption spectra of ionanofluids with different weight concentrations on the first day.

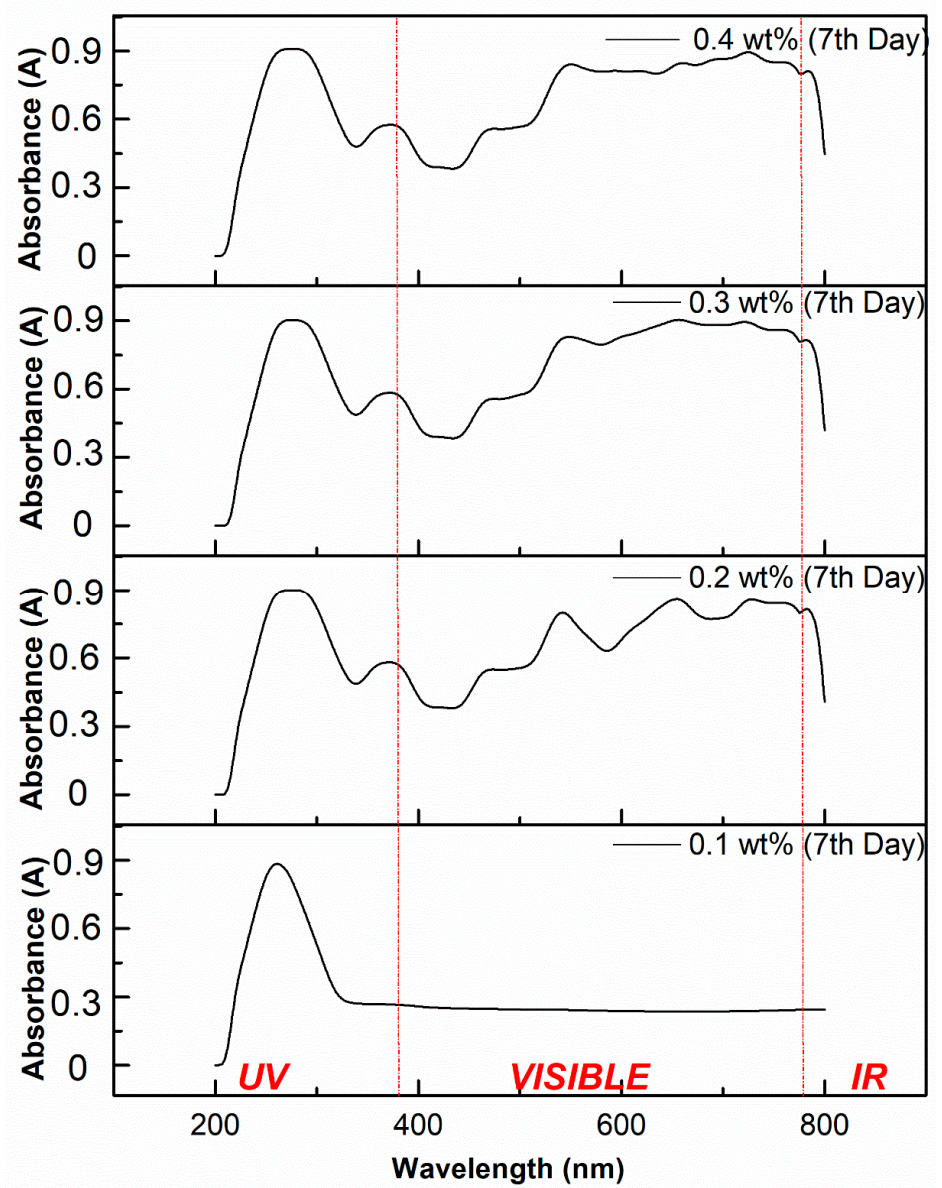

Figure 9. Absorption spectra of ionanofluids with different weight concentration on the seventh day. 
The Beer-Lambert law was applied for calculating the extinction coefficient of the as-prepared samples. Figure 10 shows the calculated extinction coefficient results at different wavelengths and nanoparticle concentrations on the first day. From the figure, it is clear that the extinction coefficient of the MXene based ionanofluids improved linearly with an increase in nanoparticle concentration. Furthermore, the extinction coefficient was higher in the UV region due to the excitation of localized surface plasmon resonance on the MXene surface [20]. While at longer wavelengths in the visible and IR regions, the optical properties resulted in less efficiency. The utmost extinction coefficient was $7.6 \mathrm{~cm}^{-1}$ for $0.4 \mathrm{wt} \%$ nanoparticle concentration, while the lowest value was obtained for $0.1 \mathrm{wt} \%$ concentration. On the other hand, the extinction coefficient of each sample decreased with an increase in wavelength.

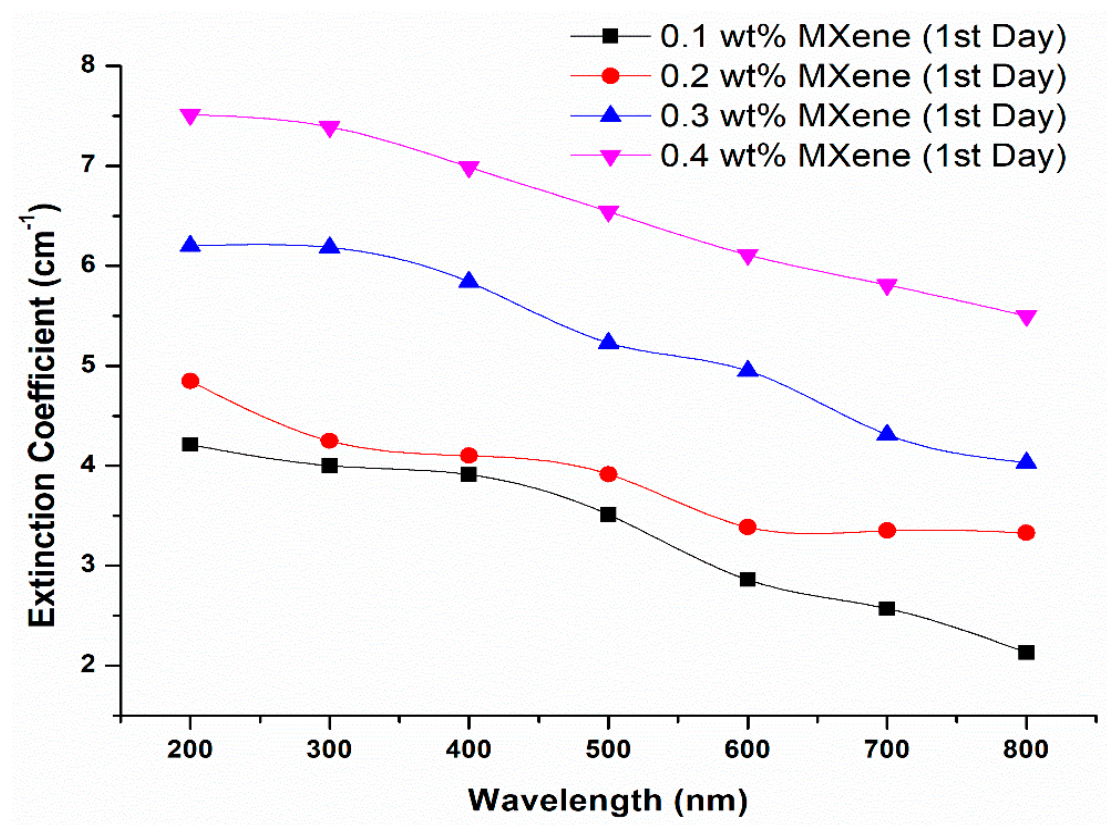

Figure 10. Effect of nanoparticle concentration towards extinction coefficient on the first day.

Figure 11 illustrates the results of the extinction coefficient of the synthesized MXene ionanofluids of $0.1,0.2,0.3$, and $0.4 \%$ weight concentrations on the seventh day. Most researchers proved that the extinction coefficient of fluids was improved by adding nanoparticles [21,22]. It is important to accurately predict the spectral characteristics of nanofluids' extinction coefficient to obtain significant optical properties at low concentrations. From the above figure, the maximum extinction coefficient value of $5.6 \mathrm{~cm}^{-1}$ was acquired for $0.4 \mathrm{wt} \%$ at $300 \mathrm{~nm}$, whereas others remained below $2.6 \mathrm{~cm}^{-1}$. From $200 \mathrm{~nm}$, the values fell desperately to $800 \mathrm{~nm}$ for the studied MXene concentrations. The obtained results were in good agreement with previous literature [3].

\subsection{Solute-Solvent Interactions}

The cumulative impact of multiple intermolecular interactions between the nanoparticles (solute) and ionic liquid-based solution (solvent - (IL + DG)) determines the mutual solubility of colloids. In general, ionic liquids (ambient temperature molten salt) contain much more complex molecular forces or interactions than traditional salts. In ionic liquid-solute mixtures, a combination of high coulombic interactions with weak spatial interactions affects the structure of nanoparticles. These spatial interactions are due to the intermolecular forces that occur between the closed-shell molecules. The different types of intermolecular forces are illustrated in Figure 12. Indeed, ionic liquids are utilized as stabilizers to facilitate the dispersion of nanoparticles with base fluid due to their ability to develop electrostatic forces on the nanoparticle surface [23]. For ionic liquids made up of cations [Emim] and anions $\left[\mathrm{OSO}_{4}\right]$, the electrostatic forces are appreciable. In such situations, ion clusters with positive or negative charges surround the 
nanoparticles' surface instead of separate individual ions to form an electro-double layer, which provides the electrostatic force to hold them separate. The force-distance curve of the Atomic Force Microscopy (AFM) results predicted that MXene nanoparticles in the binary mixture possess an ionic layer around the MXene nanoparticle that led to the formation of electrostatic forces. The formation of an electrical double layer that is responsible for preventing aggregation is shown in Figure 13. The ions of the formulated binary solution (IL + DG) get attracted to the synthesized MXene nanoparticle due to the presence of electrostatic force. Consequently, anionic semi-organized supermolecular imidazolium aggregates formed the first layer around MXene nanoparticles, while supermolecular cationic aggregates were positioned as the next layer for charging balance.

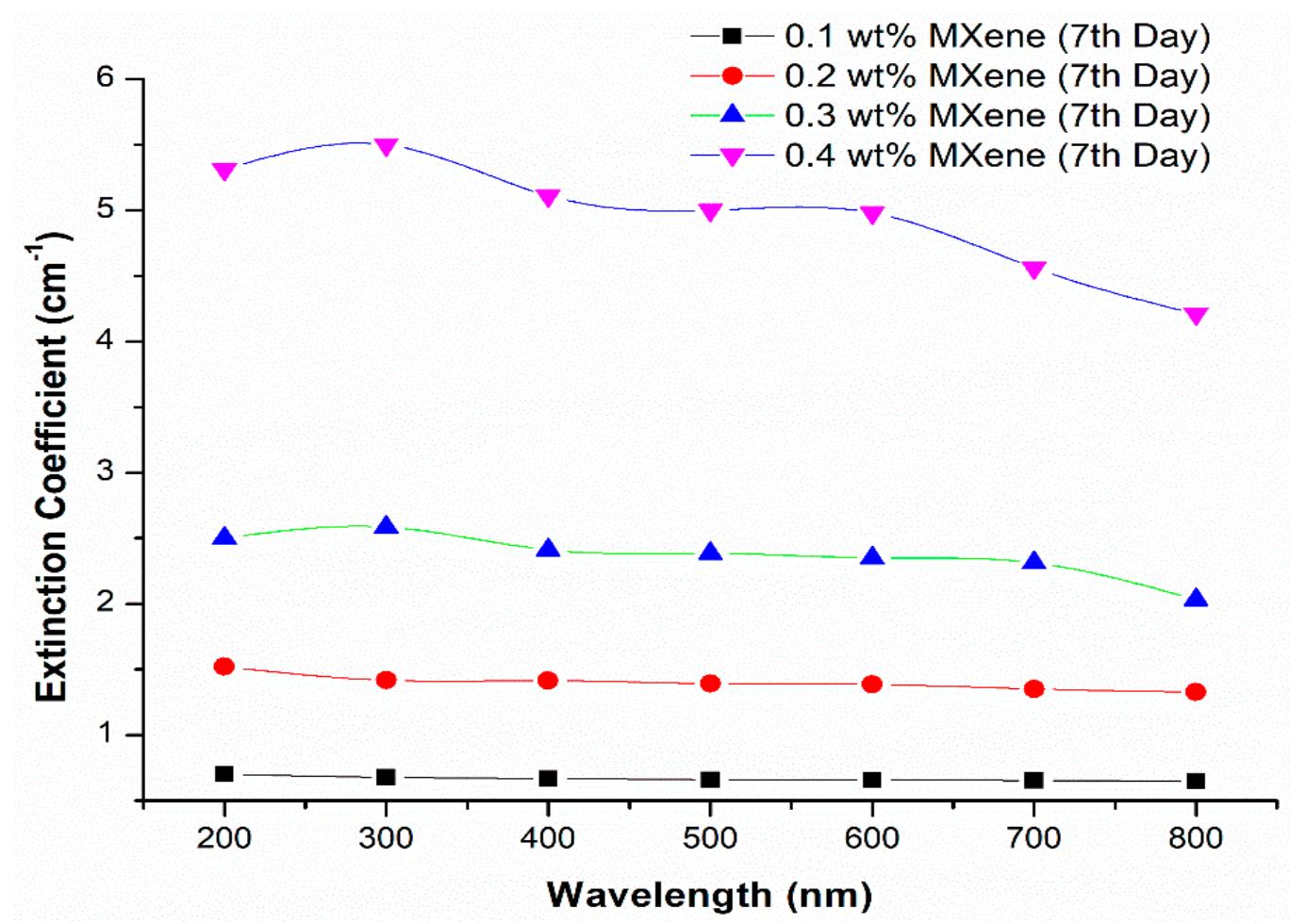

Figure 11. Effect of nanoparticle concentration toward extinction coefficient on the seventh day.

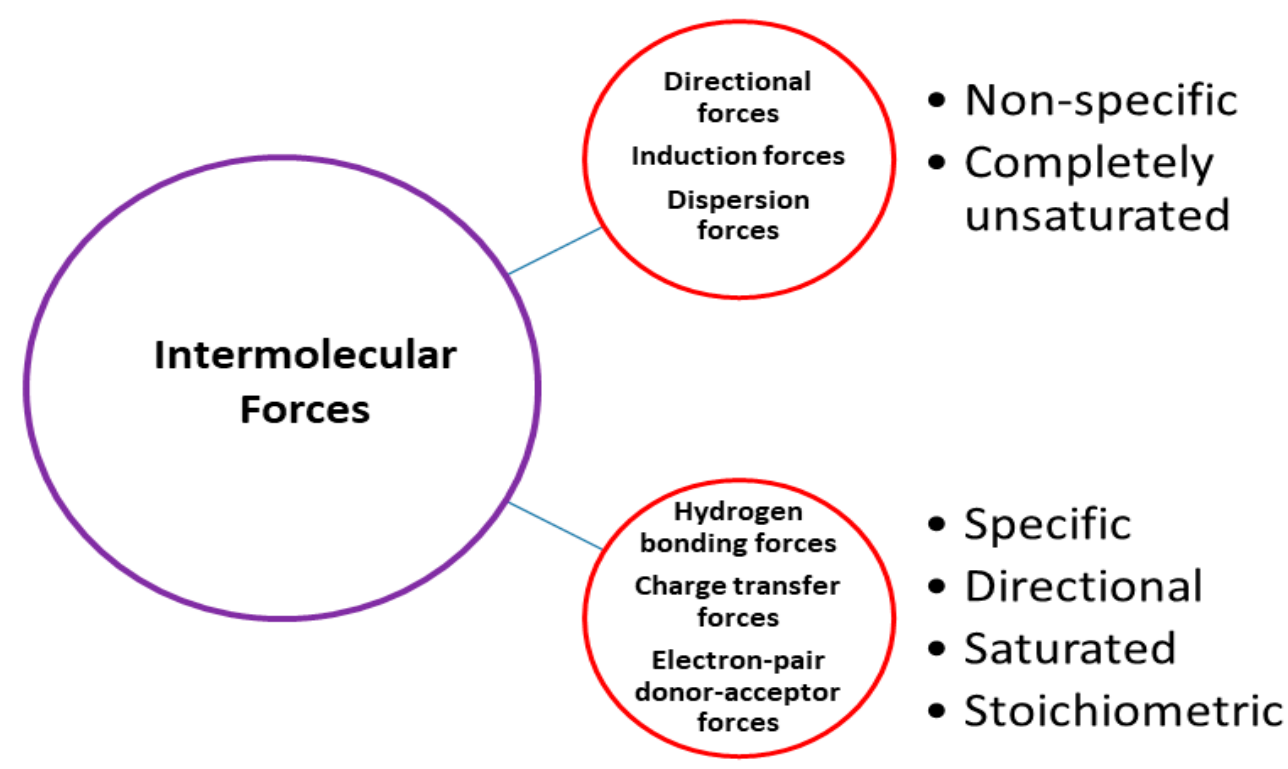

Figure 12. Types and characteristics of intermolecular forces. 


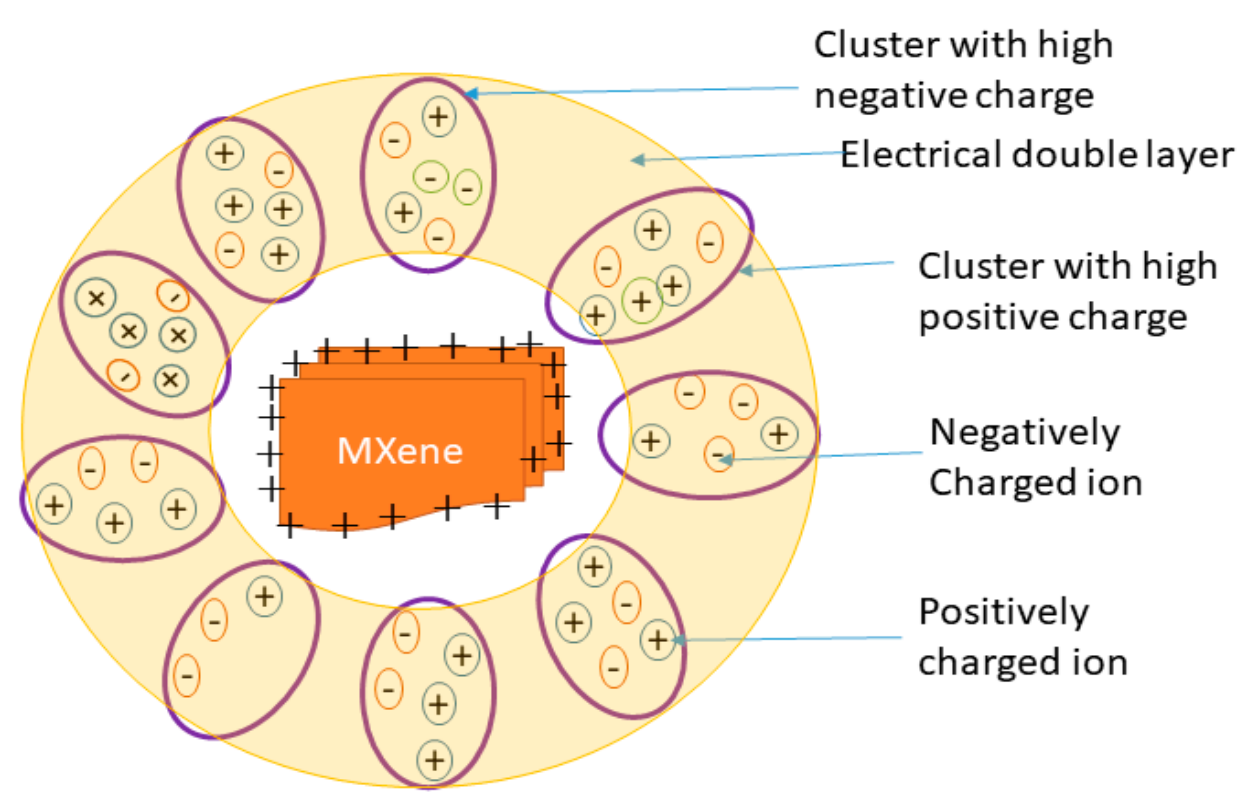

Figure 13. Electrical double-layer formation around the MXene nanoparticle.

\subsection{Stability Analysis of Ionanofluids}

\subsubsection{Visual Inspection Analysis}

The four prepared ionic liquid-based MXene nanofluids' visual appearance over 7 days after preparation is presented in Table 1. Fluids from day 5 to day 7 showed dispersed nanoparticles over the inspection time. However, slight sedimentation at the bottom of the vial could be seen (day 5 , day 6, day 7) due to the aggregation of nanoparticles that played an important role in maintaining the nanofluids' stability. Besides, the black color was becoming progressively transparent, which was linked to nanofluid stability. Moreover, the samples that displayed a dark black color over time were the most stable ionanofluids. Samples on days 5, 6, and 7 indicated evidence of slight aggregation and sedimentation. The ionic liquid-based MXene nanofluid presented good dispersion for the first four days, even without any surfactants. This may be attributed to the addition of [EMIM] $\left[\mathrm{OSO}_{4}\right]$ ionic liquids with a significant amount of surface charges resulting in electrostatic repulsion that can increase the nanofluids' stability.

Table 1. Visual inspection of the prepared samples.

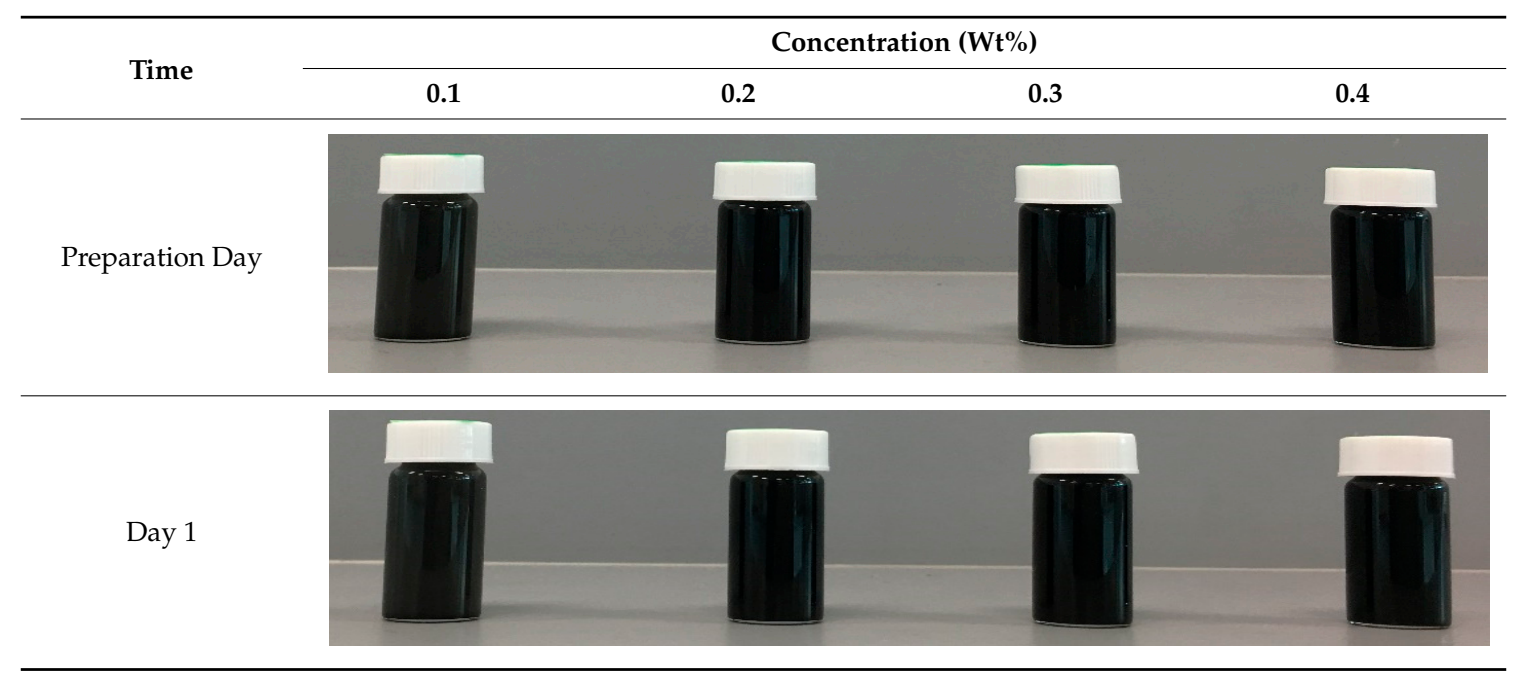


Table 1. Cont.

\begin{tabular}{|c|c|c|c|c|}
\hline \multirow{2}{*}{ Time } & \multicolumn{4}{|c|}{ Concentration (Wto) } \\
\hline & 0.1 & 0.2 & 0.3 & 0.4 \\
\hline Day 2 & & & & \\
\hline Day 3 & & & & \\
\hline Day 4 & & & & \\
\hline Day 5 & & & & \\
\hline Day 6 & & & & \\
\hline Day 7 & & & & \\
\hline
\end{tabular}

\subsubsection{Stability Analysis Using Light Absorbance}

Another way to test the stability of colloidal suspension was by measuring the change in the prepared ionanofluid samples' absorbance. On the first day and seventh day of 200 to $800 \mathrm{~nm}$ wavelength, the absorbance spectra were assessed over different MXene nanoparticle concentrations. The change of absorbance spectra of the formulated ionanofluids with concentrations ranging from 0.1 to $0.4 \mathrm{wt} \%$ is presented in Figure 14. The findings revealed that there were not any appreciable absorbance changes between the first day and seventh day. In general, Beer-Lambert's law behaves ideally for concentrations below a critical limit. However, nonlinear activity was observed at concentrations above $10 \mathrm{mM}$ for most absorbing molecules. The obtained results showed that the tested samples were non-linear, deviating from Beer-Lambert's law. This was due to interaction, association, or dissociation caused by the analyte (MXene) in the solvent (base fluid). In addition, the $\mathrm{pH}$ of the solution varied at 
a higher concentration which resulted in a resonance transition where the absorption ranges of the sample increased as the $\mathrm{pH}$ of the sample changed.

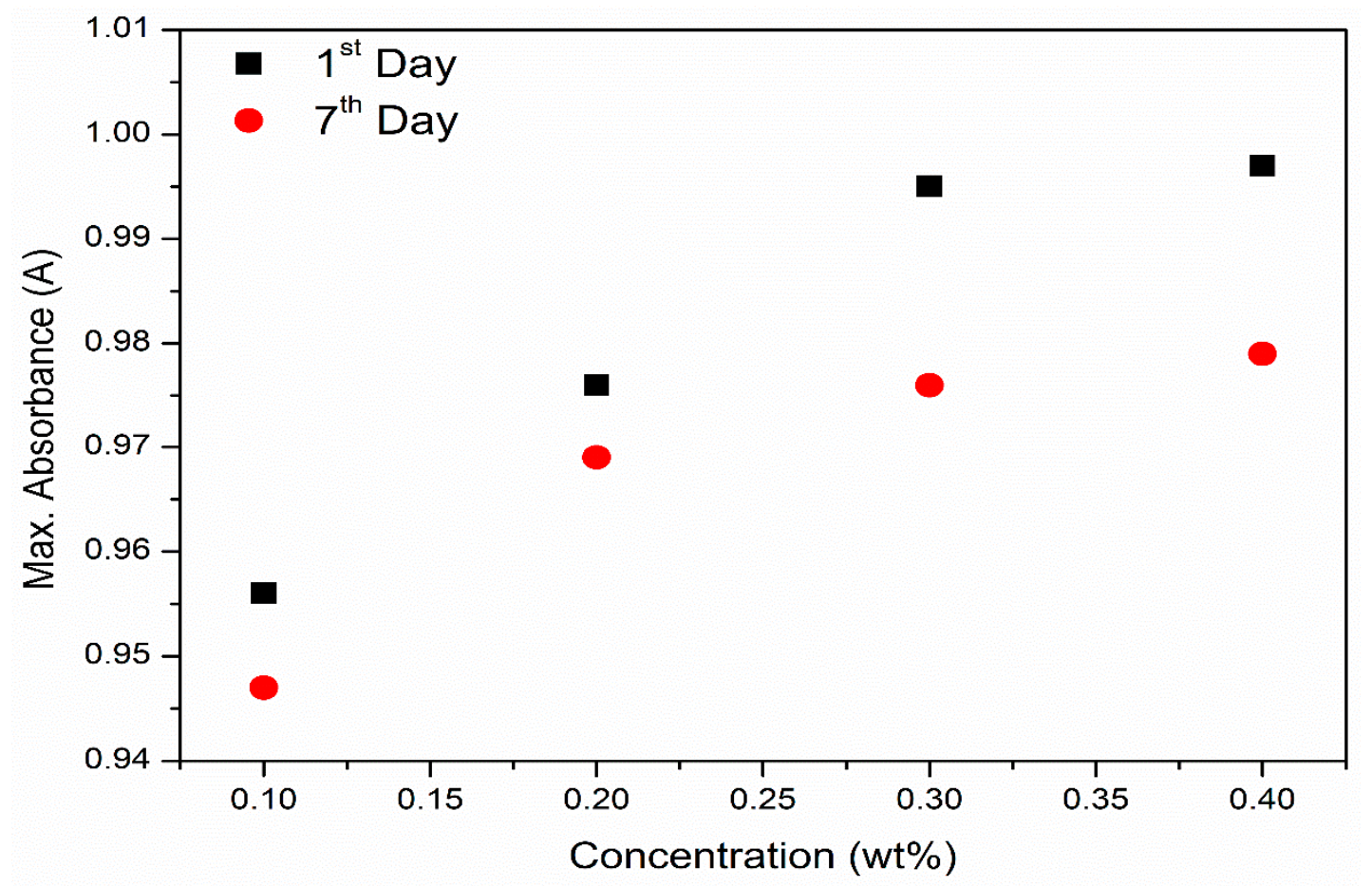

Figure 14. Absorbance analysis with respect to MXene concentration.

\section{Conclusions}

In summary, with $\mathrm{NH}_{4} \mathrm{HF}_{4}$ etchant, intercalation and ultrasonic separation were conducted to synthesize 2D MXene $\left(\mathrm{Ti}_{3} \mathrm{C}_{2}\right)$ and mix them with a binary solution of [EMIM] $\left[\mathrm{OSO}_{4}\right]$ and diethylene glycol to formulate highly efficient nanofluid for light absorbance. The impact of MXene concentration on ionic liquid-based DG/MXene nanofluid optical properties was examined through UV-Vis Spectroscopy. Through visual inspection and absorbance analysis over time, the dispersion stability of the prepared ionanofluids was evaluated. Based on the analysis of UV-Vis spectroscopy, the following points are concluded:

- The concentration of 2D MXene nanoparticles impacted a significant effect on the absorbance spectra

- With the increase in the nanoparticle loading, the absorbance capacity of the ionanofluid increased

- High extinction coefficient was obtained for fluid containing less concentration of MXene

- High absorption peaks were found on both days, which meant that the light absorbance potential over the measured wavelengths showed great stability.

The results of the stability evaluation are summarised as follows:

- Slight aggregation of nanoparticles was observed from day 5, which was monitored via a visual inspection method

- Stability analysis through absorbance spectra illustrated that the prepared ionanofluids were stable for 0.1 to $0.4 \mathrm{wt} \%$ MXene nanoparticle concentration

- Electrical conductivity improved with the addition of MXene nanoparticles, resulting in a maximum electrical conductivity of $571 \mu \mathrm{S} / \mathrm{cm}$ at $0.4 \mathrm{wt} \%$. 
Author Contributions: Conceptualisation, B.B.; methodology, B.B.; formal analysis, R.S.; investigation, B.B.; resources, N.A.; data curation, B.B.; writing—original draft preparation, B.B.; writing-review and editing, R.S.; supervision, K.H.; project administration, R.S.; funding acquisition, K.H. and A.R.; extinction coefficient analysis, A.R.; grammar checking, A.R. All authors have read and agreed to the published version of the manuscript.

Funding: The APC was funded by Charles Darwin University, Australia.

Acknowledgments: The authors wish to recognize Universiti Teknologi PETRONAS for their research support through YUTP FRG grant (Grant No. 015LC0-118).

Conflicts of Interest: The authors declare no conflict of interest.

\section{References}

1. Adhami Dehkordi, R.; Hemmat Esfe, M.; Afrand, M. Effects of functionalized single walled carbon nanotubes on thermal performance of antifreeze: An experimental study on thermal conductivity. Appl. Therm. Eng. 2017, 120, 358-366. [CrossRef]

2. Lee, Y.; Jeong, H.; Park, J.-T.; Delgado, A.; Kim, S. Experimental Investigation on Evaluation of Thermal Performance of Solar Heating System Using $\mathrm{Al}_{2} \mathrm{O}_{3}$ Nanofluid. Appl. Sci. 2020, 10, 5521. [CrossRef]

3. Huang, J.; Chen, Z.; Du, Z.; Xu, X.; Zhang, Z.; Fang, X. A highly stable hydroxylated graphene/ethylene glycol-water nanofluid with excellent extinction property at a low loading for direct absorption solar collectors. Thermochim. Acta 2020, 684, 178487. [CrossRef]

4. Gheymasi, A.N.; Rajabi, Y.; Zare, E.N. Nonlinear optical properties of poly(aniline-co-pyrrole)@ ZnO-based nanofluid. Opt. Mater. 2020, 102, 109835. [CrossRef]

5. Aguilar, T.; Sani, E.; Mercatelli, L.; Carrillo-Berdugo, I.; Torres, E.; Navas, J. Exfoliated graphene oxide-based nanofluids with enhanced thermal and optical properties for solar collectors in concentrating solar power. J. Mol. Liq. 2020, 306, 112862. [CrossRef]

6. Li, X.; Zeng, G.; Lei, X. The stability, optical properties and solar-thermal conversion performance of SiC-MWCNTs hybrid nanofluids for the direct absorption solar collector (DASC) application. Sol. Energy Mater. Sol. Cells 2020, 206, 110323. [CrossRef]

7. Valizade, M.; Heyhat, M.M.; Maerefat, M. Experimental comparison of optical properties of nanofluid and metal foam for using in direct absorption solar collectors. Sol. Energy Mater. Sol. Cells 2019, 195, 71-80. [CrossRef]

8. Di Rosa, D.; Wanic, M.; Fal, J.; Żyła, G.; Mercatelli, L.; Sani, E. Optical and dielectric properties of ethylene glycol-based nanofluids containing nanodiamonds with various purities. Powder Technol. 2019, 356, 508-516. [CrossRef]

9. Zhang, L.; Liu, J.; He, G.; Ye, Z.; Fang, X.; Zhang, Z. Radiative properties of ionic liquid-based nanofluids for medium-to-high-temperature direct absorption solar collectors. Sol. Energy Mater. Sol. Cells 2014, 130, 521-528. [CrossRef]

10. Bakthavatchalam, B.; Habib, K.; Saidur, R.; Saha, B.B.; Irshad, K. Comprehensive study on nanofluid and ionanofluid for heat transfer enhancement: A review on current and future perspective. J. Mol. Liq. 2020, 305, 112787. [CrossRef]

11. Das, L.; Habib, K.; Saidur, R.; Aslfattahi, N.; Yahya, S.M.; Rubbi, F. Improved Thermophysical Properties and Energy Efficiency of Aqueous Ionic Liquid/MXene Nanofluid in a Hybrid PV/T Solar System. Nanomaterials 2020, 10, 1372. [CrossRef] [PubMed]

12. Abdelrazik, A.S.; Tan, K.H.; Aslfattahi, N.; Arifutzzaman, A.; Saidur, R.; Al-Sulaiman, F.A. Optical, stability and energy performance of water-based MXene nanofluids in hybrid PV/thermal solar systems. Sol. Energy 2020, 204, 32-47. [CrossRef]

13. Bao, Z.; Bing, N.; Zhu, X.; Xie, H.; Yu, W. Ti3C2Tx MXene Contained Nanofluids with High Thermal Conductivity, Super Colloidal Stability and Low Viscosity. Chem. Eng. J. 2020, 126390. [CrossRef]

14. Bakthavatchalam, B.; Habib, K.; Saidur, R.; Irshad, K.; Hussein, O.A. An investigation of thermal stability and heat capacity of imidazolium based ionic liquids at elevated temperature. IOP Conf. Ser. Mater. Sci. Eng. 2020, 863, 012026. [CrossRef]

15. Aslfattahi, N.; Saidur, R.; Arifutzzaman, A.; Sadri, R.; Bimbo, N.; Sabri, M.F.M.; Maughan, P.A.; Bouscarrat, L.; Dawson, R.J.; Said, S.M.; et al. Experimental investigation of energy storage properties and thermal conductivity of a novel organic phase change material/MXene as A new class of nanocomposites. J. Energy Storage 2020, 27, 101115. [CrossRef] 
16. Liu, G.; Shen, J.; Liu, Q.; Liu, G.; Xiong, J.; Yang, J.; Jin, W. Ultrathin two-dimensional MXene membrane for pervaporation desalination. J. Memb. Sci. 2018, 548, 548-558. [CrossRef]

17. Ding, L.; Wei, Y.; Wang, Y.; Chen, H.; Caro, J.; Wang, H. A Two-Dimensional Lamellar Membrane: MXene Nanosheet Stacks. Angew. Chem. 2017, 129, 1851-1855. [CrossRef]

18. Szuplewska, A.; Kulpińska, D.; Dybko, A.; Jastrzębska, A.M.; Wojciechowski, T.; Rozmysłowska, A.; Chudy, M.; Grabowska-Jadach, I.; Ziemkowska, W.; Brzózka, Z.; et al. 2D Ti2C (MXene) as a novel highly efficient and selective agent for photothermal therapy. Mater. Sci. Eng. C 2019, 98, 874-886. [CrossRef]

19. Keaveney, S.T.; Haines, R.S.; Harper, J.B. Reactions in Ionic Liquids. In Encyclopedia of Physical Organic Chemistry; American Cancer Society: Atlanta, GA, USA, 2017; pp. 1-54. ISBN 9781118468586.

20. Duan, H. Analysis on the extinction properties of nanofluids for direct solar absorption. Phys. E Low-Dimens. Syst. Nanostruct. 2020, 120, 114046. [CrossRef]

21. Chen, W.; Zou, C.; Li, X. Application of large-scale prepared MWCNTs nanofluids in solar energy system as volumetric solar absorber. Sol. Energy Mater. Sol. Cells 2019, 200, 109931. [CrossRef]

22. Tan, J.; Xie, Y.; Wang, F.; Jing, L.; Ma, L. Investigation of optical properties and radiative transfer of $\mathrm{TiO}_{2}$ nanofluids with the consideration of scattering effects. Int. J. Heat Mass Transf. 2017, 115, 1103-1112. [CrossRef]

23. Bakthavatchalam, B.; Habib, K.; Wilfred, C.D.; Saidur, R.; Saha, B.B. Comparative evaluation on the thermal properties and stability of MWCNT nanofluid with conventional surfactants and ionic liquid. J. Therm. Anal. Calorim. 2020. [CrossRef]

Publisher's Note: MDPI stays neutral with regard to jurisdictional claims in published maps and institutional affiliations. 